\title{
LABORATÓRIOS DO GRUPO DE PESQUISA MINERALOGIA E GEOQUÍMICA APLICADA - GMGA
}

\section{LaMiGA - Laboratório de Mineralogia, Geoquímica e Aplicações}

\section{COORDENADOR}

Marcondes Lima da Costa, Bolsista de Produtividade em Pesquisa do CNPq, nível 1A, líder do Grupo de Pesquisa do CNPq, Mineralogia e Geoquímica Aplicada GMGA

\section{VÍNCULO}

Professor Titular do Instituto de Geociências (UFPA) e professor-orientador do Programa de Pós-Graduação em Geologia e Geoquímica (PPGG) da UFPA

\section{INSTITUIÇÃO}

Universidade Federal do Pará (UFPA)

Cidade Universitária Prof. José da Silveira Netto, Campus do Guamá,

Setor Básico (Campus I)

Rua Augusto Correa, 1, Guamá.

66075-110, Belém, Pará, Brasil

\section{EQUIPE}

- Dra. Glayce Jholy S.S. Valente, bolsista do Programa Nacional de Pós Doutorado da CAPES, PPGG-IG-UFPA

- MSc. Igor Alexandre Rocha Barreto, doutorando do PPGG-IG-UFPA

- Prof. Dr. Nilson dos Santos Ferreira, professor Adjunto I da Universidade Federal do Sergipe (UFS) 
- Dra. Darilena Monteiro Porfírio, analista química - Centrais Elétricas do Norte do Brasil, LACEN

- MSc. Pabllo Henrique Costa dos Santos, técnico em mineração do Museu de Geociências (IG-PPGG) e doutorando do PPGG-IG-UFPA

- Bacharel em geologia Rayara do Socorro Souza da Silva, mestranda do PPGG-IG-UFPA

\section{LABORATÓRIOS}

- $\quad$ LaMiGA - ICP-MS/LIBS

- $\quad$ LaMiGA - Raios X/MEV

- $\quad$ LaMiGA - FTIR/ATD-TG/BET

- LaMiGA - MINERALOGIA/GEMOLOGIA

- $\quad$ LaMiGA - MÖSSBAUER 


\section{Universidade Federal do Pará Instituto de Geociências}

Programa de P6s-Graduação em Geologia e Geoquímica

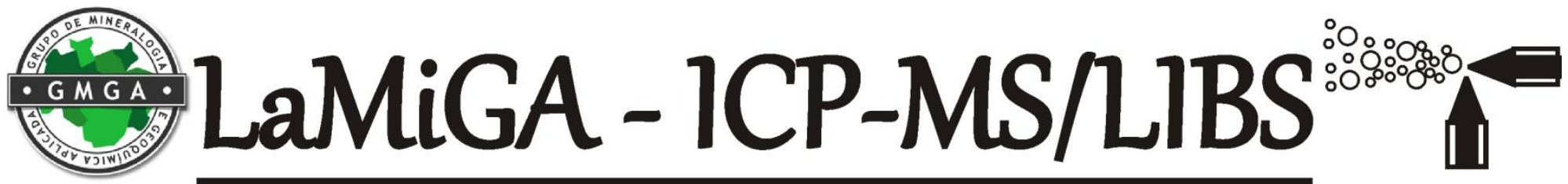

\section{Laboratório de Mineralogia, Geoquímica e Aplicações}

(ICP-MS, LIBS, CROMATÓGRAFO DE ÍONS, ESPECTROFOTÔMETRO)

Responsável: Prof. Dr. Marcondes Lima da Costa

Contatos: 3201-7428/marcondeslc@gmail.com 


\section{RECURSOS HUMANOS}

EQUIPE: Dra. Glayce Jholy S.S. Valente

Dra. Darilena Monteiro Porfírio

\section{INSTALACÕES}

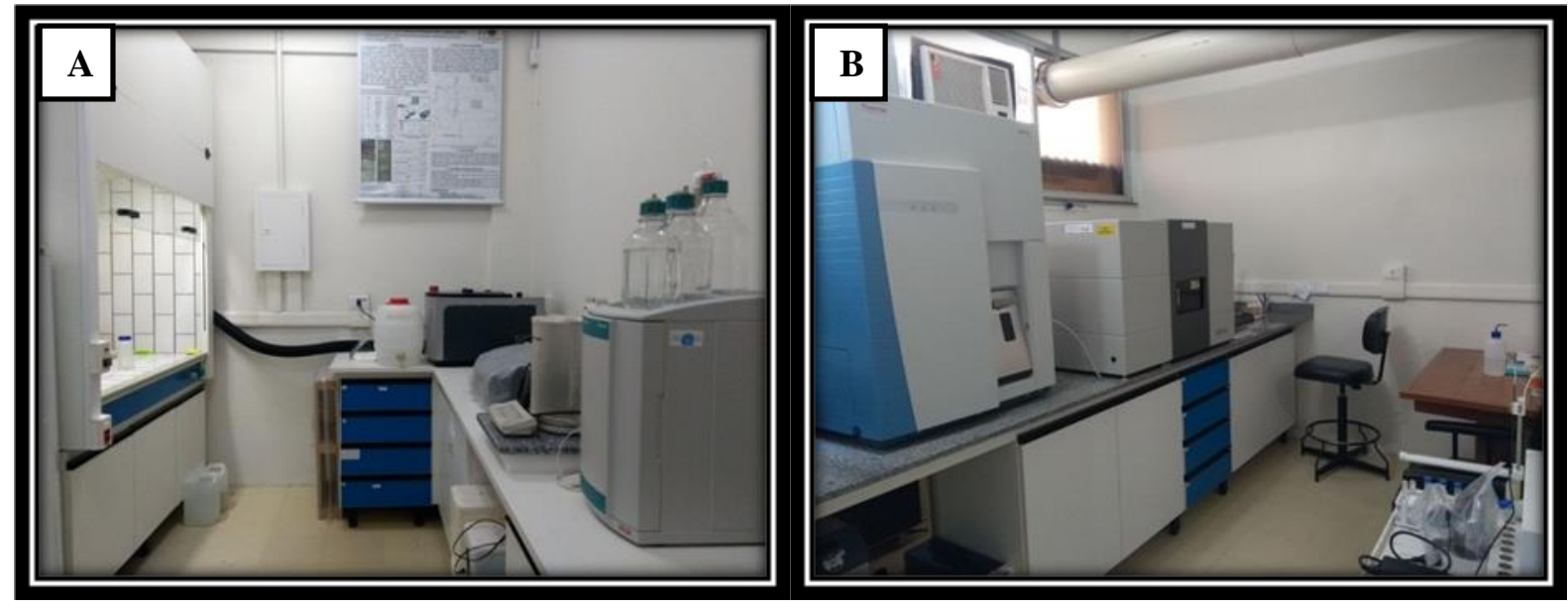

Figura 1. Estrutura física do laboratório. A - Antessala onde ocorre o preparo de amostras comporta microondas, destilador de ácido e capela com exaustor. B - Espaço que abriga o Espectrômetro de Massas com Plasma Indutivamente Acoplado (ICP-MS, do inglês) e o Espectrômetro de Emissão em Plasma Induzido por Laser (LIBS, do inglês).

\section{HISTÓRICO DO LABORATÓRIO}

O laboratório foi criado a partir de uma antiga sala de aula do PPGG, térreo, prédio sede do Instituto de Geociências da UFPA, Campus do Guamá, Setor Básico (Campus I) (Figura 2). O espaço atravessou um longo período de reformas iniciado em 2013 e finalizado em 2014 para atender as necessidades físicas, elétricas e hidráulicas do Espectrômetro de Massas com Plasma Indutivamente Acoplado (ICP-MS). Além dos cuidados com o espaço interno do laboratório, também houve necessidade em se providenciar um abrigo de gases e uma calçada que facilitasse o acesso ao abrigo, adjacente ao laboratório. Após a finalização da obra civil, instalação de mobiliário, capela e dutos de exaustão a instalação e treinamento operacional do ICP-MS (iCAP Qc, Thermo Fisher Scientific, Bremen, Germany), acompanhado de Chiller 
(ThermoFlex 2500, Thermo Fisher Scientific, Bremen, Germany), bomba de vácuo (SV40BIFC 960365V2016, Oerlikon Leybold), software (1.5.1189.31, Thermo Fisher Scientific, Bremen, Germany), computador e amostrador automático (ASX-520, CETAC) fora instalado em julho de 2014 pela técnica, a química de aplicação Valeska Meirelles Sousa, da empresa Analítica, com duração de 20h. Na seqüência, ocorreu a instalação e treinamento operacional do sistema de digestão induzida por radiação microondas (Berghof, modelo SpeedWave 4) e do destilador de ácido sub-boiling (Berghof). Em agosto de 2016 o laboratório recebeu novo equipamento, desta vez, o Espectrômetro de Emissão em Plasma Induzido por Laser (LIBS), de marca Applied Spectra e modelo J200 Tandem, cuja instalação e treinamento operacional ocorreram em setembro do mesmo ano pelo técnico Luiz Rinaldo Bizaio, representante da Bizaio Comércio de Instrumentos de Medida Ltda. Com a garantia de determinação simultânea de elementos isótopos maiores e traços via análise direta em materiais sólidos, o acoplamento entre ICP-MS e LIBS concretizou-se em março de 2018, com a visita do técnico Luiz Rinaldo Bizaio. 


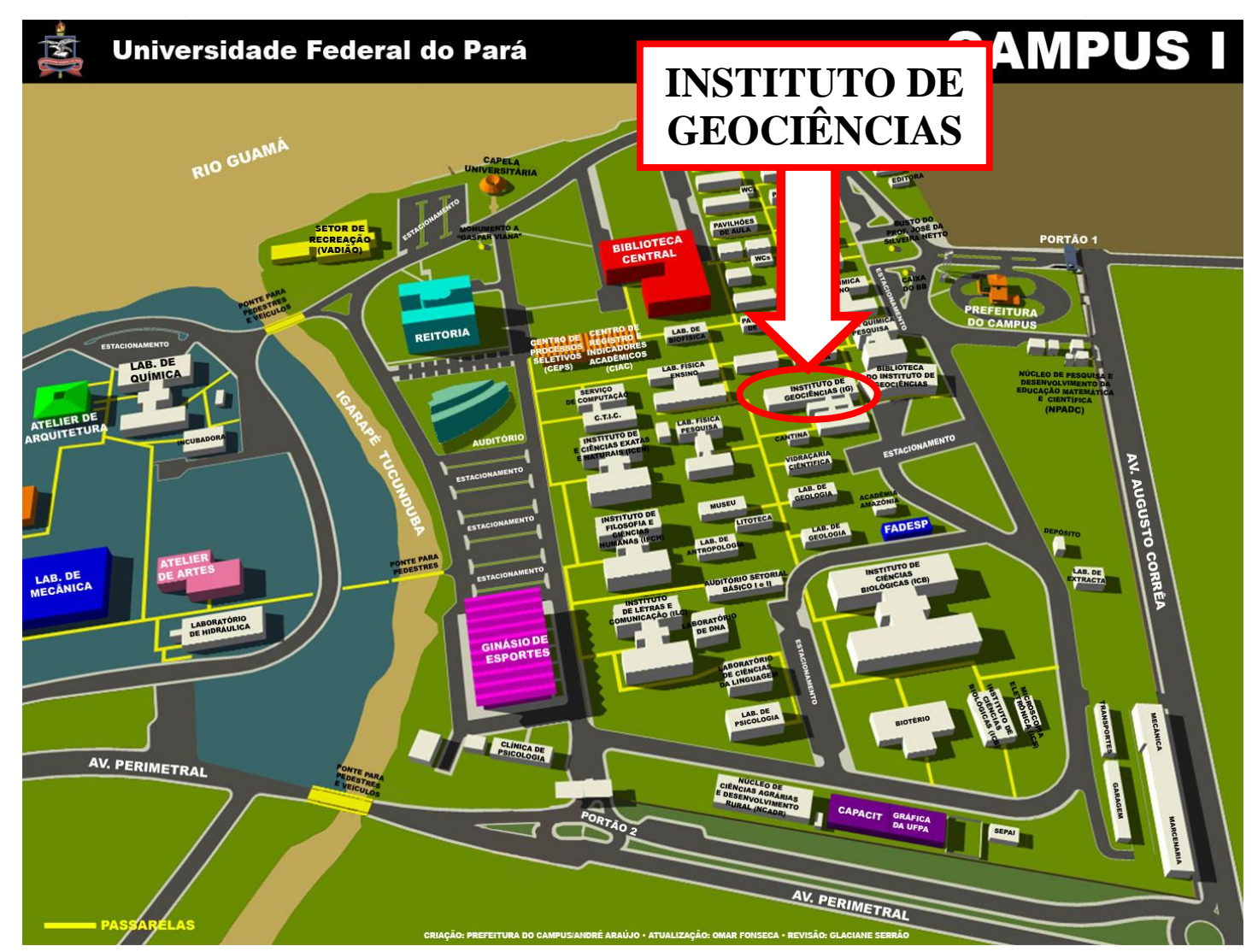

Figura 2. Localização do LaMiGA - ICP-MS/LIBS. Instituto de Geociências, Cidade Universitária Professor José da Silveira Netto, Campus do Guamá, Setor Básico (Campus I). FONTE: modificada de prefeitura.ufpa.br. 


\section{RELAÇÃO DE EQUIPAMENTOS}

\section{ICP-MS}

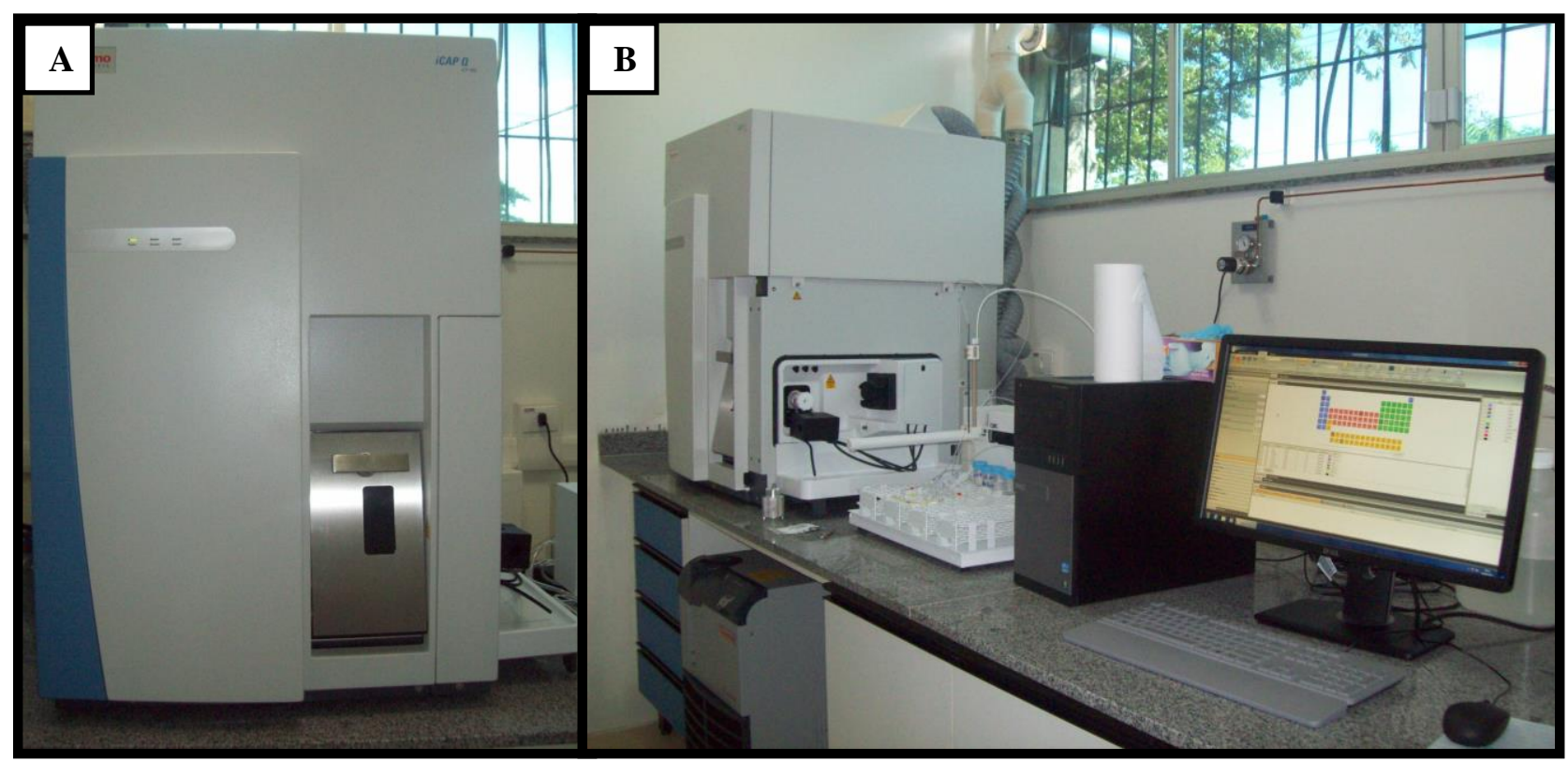

Figura 3. A - Vista frontal do ICP-MS. B - Vista lateral direita do ICP-MS, no detalhe o amostrador automático, computador, abaixo o Chiller, ao fundo sistema de exaustão e linha de gases.

Marca e modelo: THERMO / iCAP Qc

Financiador: 011006400-0733/10 FINEP/FNDCT

Identificação FADESP: RI-2.1.1.300713

Projeto FADESP: 2786

\subsection{PRINCÍPIOS E APLICAÇÕES}

O espectrômetro de massa com plasma indutivamente acoplado (ICP-MS) é ideal para realização de análises qualitativas e quantitativas multielementares em solução. Oferece limites de detecção na faixa de sub partes por trilhão na determinação de mais de 70 elementos simultaneamente e seus respectivos isótopos, o que somado a agilidade das determinações transcende vantagens sobre outras técnicas espectroscópicas atômicas. O suporte analítico ofertado pela técnica garante aplicabilidade em diversos setores na área industrial e acadêmica. 


\section{LIBS}

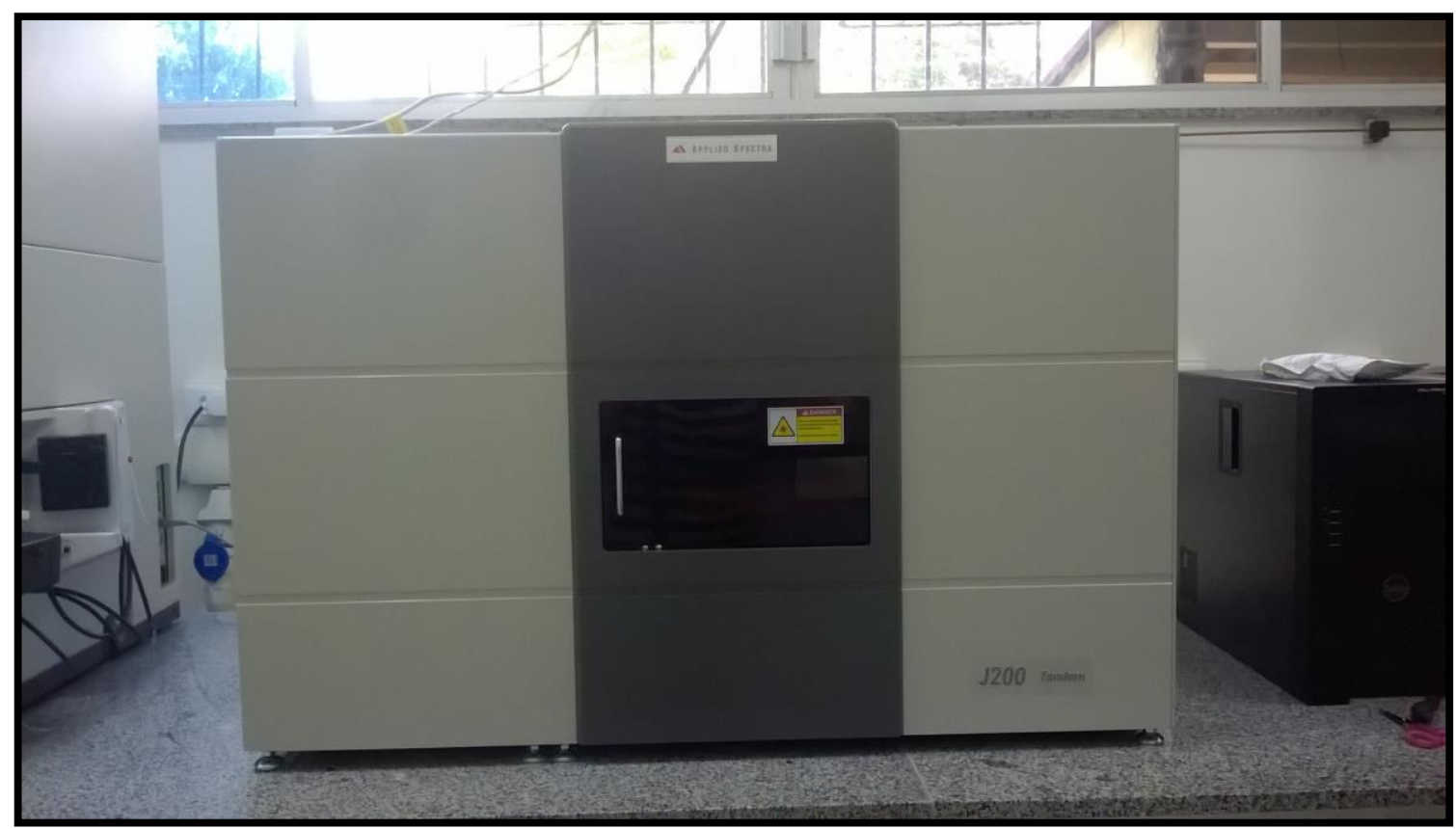

Figura 4. Vista frontal do LIBS.

Marca e modelo: APPLIED SPECTRA / J200 Tandem

Financiador: 01.13.0477.00 277 FINEP/FNDCT

Identificação FADESP: 19/3.1.1.050416

Projeto FADESP: 3435

\subsection{PRINCÍPIOS E APLICAÇÕES}

A Espectrometria de Emissão de Plasma Induzido por Laser, do inglês Laser Induced Breakdown Spectroscopy (LIBS), destaca-se entre as técnicas espectrofotométricas modernas. Seu diferencial entre as demais consta no uso de pulsos de laser como fonte de alta energia para vaporizar a amostra, seja condutora (metálicas) ou não (semicondutores ou isoladores), e excitar a radiação de emissão eletromagnética obtendo informação qualitativa e quantitativa simultaneamente de um amplo conjunto de elementos, incluindo os mais leves, como $\mathrm{H}, \mathrm{Be}, \mathrm{Li}, \mathrm{C}, \mathrm{O}, \mathrm{Na}$ e $\mathrm{Mg}$, o que a torna um potencial técnica na análise direta micro e essencialmente não-destrutiva.

Sua aplicabilidade engloba um universo de matrizes em distintas áreas do setor industrial e acadêmico, desde que entre as vantagens ofertadas pela técnica consiste da eliminação do pré-tratamento da amostra, potencializando tempo e custos operacionais. 
Também se faz bastante aceitável em trabalhos de conservação e restauração, por preservar a integridade de materiais arqueológicos e objetos de arte diante à sua baixa invasividade, contribuindo ainda para o processo de limpeza em peças de arte para remoção de incrustações superficiais sob ação do laser.

\section{MICROONDAS}

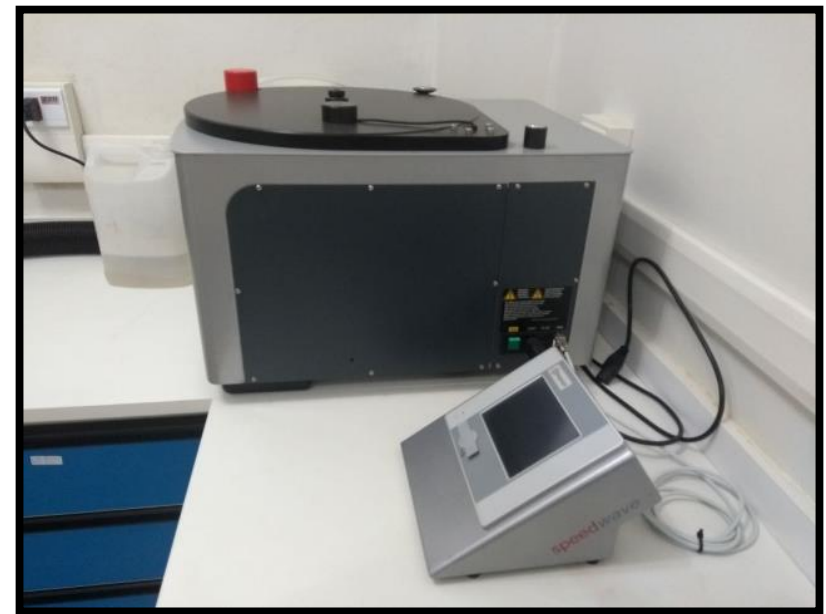

Figura 5. Vista frontal do digestor de amostra por micro-ondas. Não operando.

Marca e modelo: Berghof / Speedwave 4.

Projeto: Pró Equipamentos.

\subsection{PRINCÍPIOS E APLICAÇÕES}

Em procedimentos de digestão de amostras assistidas por radiação micro-ondas, trabalha-se com o aumento do ponto de ebulição do ácido durante o período reacional amostra-ácido(s). Isto é alcançado quando da aplicação da energia da radiação em frasco fechado que provoca o aumento da pressão deste e por conseqüência diminui drasticamente o tempo requerido para digerir uma amostra quando comparada a procedimentos de aquecimento convencionais que empregavam chapas ou blocos digestores, pois nestes casos, a temperatura máxima obtida era a do ponto de ebulição do(s) ácido(s) empregado (s).

Além deste benefício, sistemas que exploram a radiação micro-ondas em frascos fechados evita também, a perda de elementos voláteis, geração de vapores ácidos no 
laboratório, contaminação de amostras, e auxilia na redução dos brancos e automatiza o processo de digestão dada à possibilidade de programação via controlador.

\section{CROMATÓGRAFO DE ÍONS}

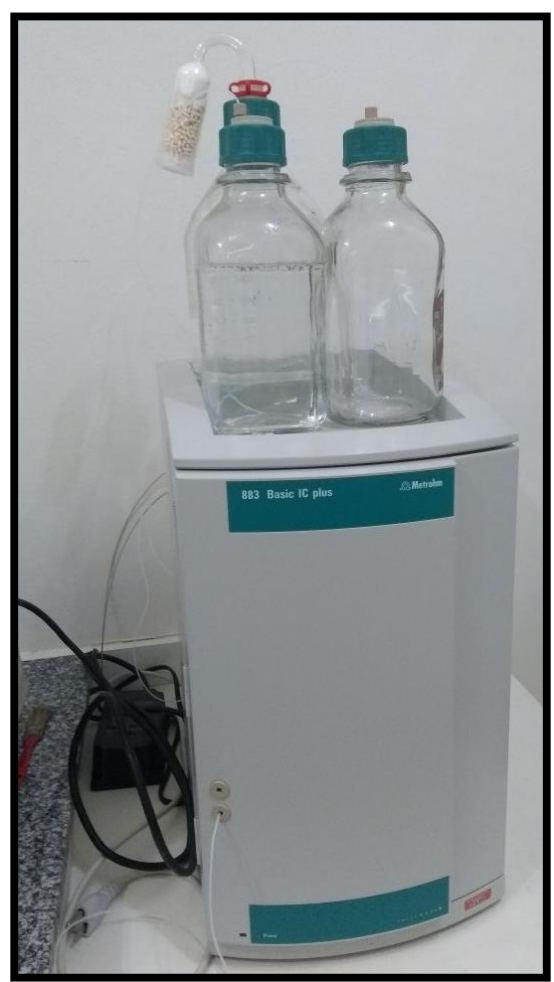

Figura 6. Vista frontal do cromatógrafo de íons.

Marca e modelo: Metrohm / 883 Basic IC Plus

Tombamento Universidade Federal do Pará: 218.008

\subsection{PRINCÍPIOS E APLICAÇÕES}

Trata-se de um método físico para separar componentes de uma mistura. A separação dá-se em duas fases, fase estacionária e fase móvel. Íons de interesse (cátions ou ânions) dissolvidos em fase móvel movem-se em direção à superfície ionicamente carregada da fase estacionária e lá são adsorvidos. A técnica aplica-se na determinação de ânions ou substâncias polares com ou sem supressão química ou de cátions. É adequada ao processamento de produtos químicos, amostras inflamáveis, água (potável, mineral, do mar, da chuva), urina. 


\section{ESPECTROFOTÔMETRO UV/VIS}

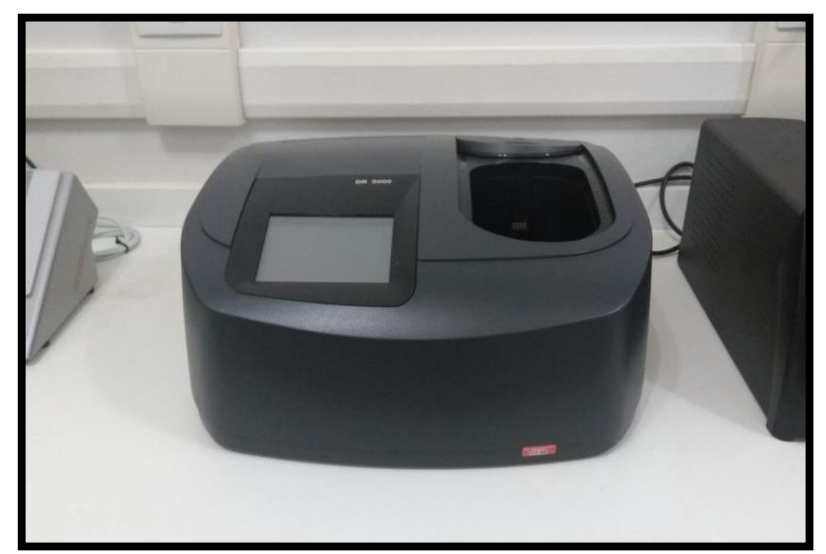

Figura 7. Vista frontal do espectrofotômetro.

Marca / modelo: Hach / DR 5000

Tombamento Universidade Federal do Pará: 218.009

\subsection{PRINCÍPIOS E APLICAÇÕES}

Uma das técnicas analíticas básicas mais amplamente empregadas em laboratórios de análises químicas e clínicas. Baseia-se na medida quantitativa de luz absorvida em uma determinada solução, cujo preparo envolve reações entre o composto a ser determinado e reagentes cromogênicos, originado uma solução colorida. A concentração na solução do analito é proporcional à quantidade de luz absorvida. Pode ser aplicada tanto em amostras líquidas, bebidas, água (potável, industrial, chuva) quanto soluções aquosas obtidas da digestão química de amostras sólidas, produtos farmacêuticos, alimentícios, rochas, solos, etc. 
Universidade Federal do Pará Instituto de Geociências

Programa de Pós-Graduação em Geologia e Geoquímica

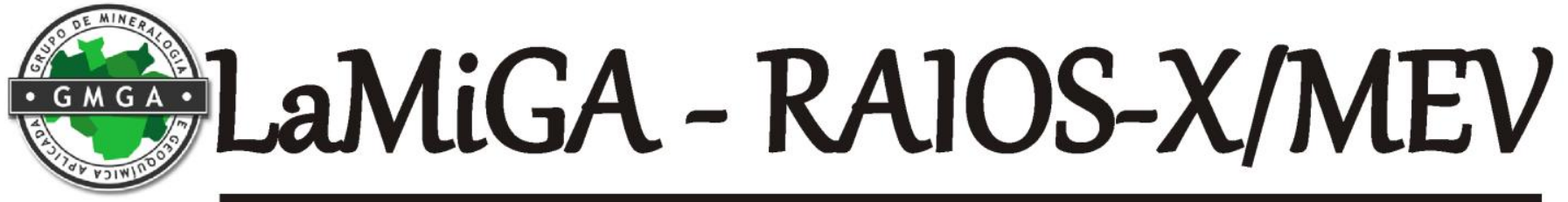

Laboratório de Mineralogia, Geoquímica e Aplicações

(DRX, FRX, $\mu$-FRX, MEV-SED, GRANULÔMETRO A LASER)

Responsável: Prof. Dr. Marcondes Lima da Costa

Contatos: 3201-7428/marcondeslc@gmail.com 


\section{RECURSOS HUMANOS}

EQUIPE: Dra. Glayce Jholy S.S. Valente

MSc. Pabllo Henrique Costa dos Santos

\section{INSTALACÕES}

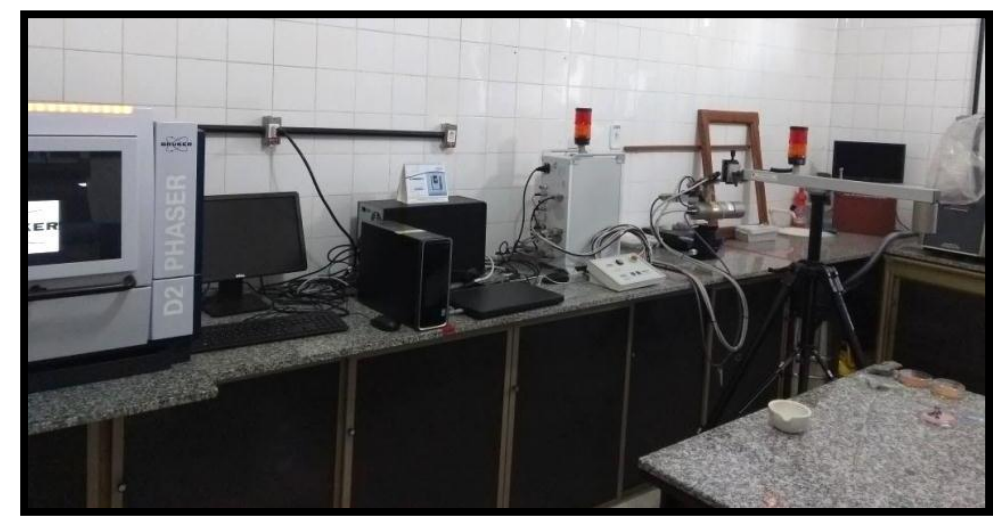

Figura 8. Estrutura física do LaMiGA - Raios X/MEV.

\section{HISTÓRICO DO LABORATÓRIO}

Paulatinamente, o espaço que era apenas uma sala de estudo ocupada por estudantes de pós-graduação, transformou-se em laboratório. A $1^{\text {a }}$ sala do lado esquerdo, da entrada do prédio do Museu de Geociências, Campus do Guamá, Setor Básico (Campus I), sofreu algumas intervenções físicas e elétricas, quando da instalação de bancadas em pedra, capela de exaustão, armários, aterramento, entre outros. Os primeiros equipamentos a serem instalados, entre 2010 e 2011, foram o MEV de bancada com Sistema de Energia Dispersivo, o Grain Size, analisador de tamanho de partículas por difração a laser, logo em seguida o Cromatógrafo de Íons, transferido para o LaMiGA - ICP-MS / LIBS. Também se encontra neste mesmo espaço o Espectrômetro portátil por Fluorescência de Raios-X, instalado em 2013. E, os mais recentes, a DRX e FRX, ambos de bancada, além da $\mu$-FRX portátil, instalada em julho de 2015 . 


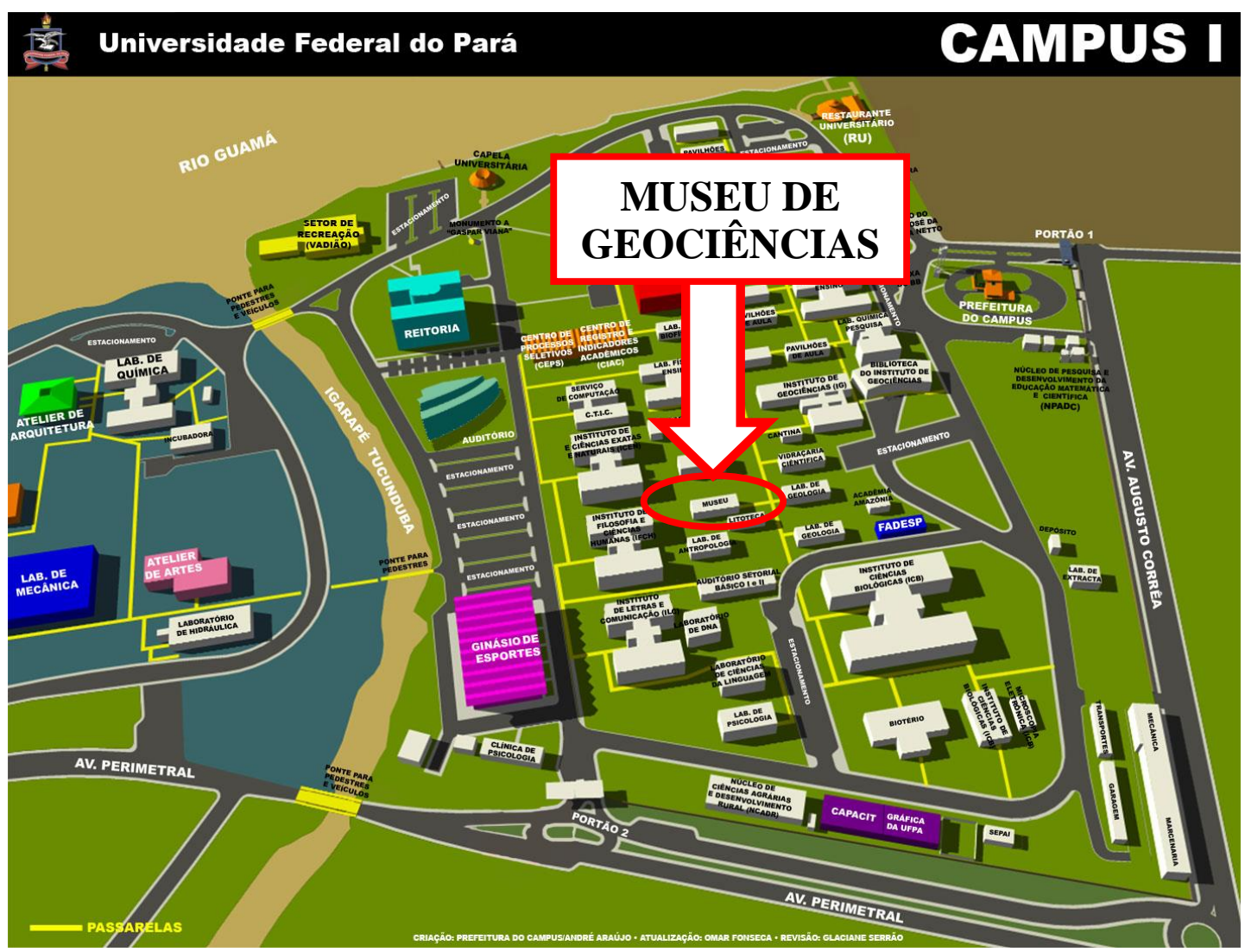

Figura 9. Localização do LaMiGA - RAIOS X/MEV. Museu de Geociências - Instituto de Geociências, Cidade Universitária Professor José da Silveira Netto, Campus do Guamá, Setor Básico (Campus I). FONTE: modificada de prefeitura.ufpa.br. 


\section{RELAÇ̃̃O DE EQUIPAMENTOS}

1. ANALISADOR DE TAMANHO DE PARTÍCULAS POR DIFRAÇÃo A LASER

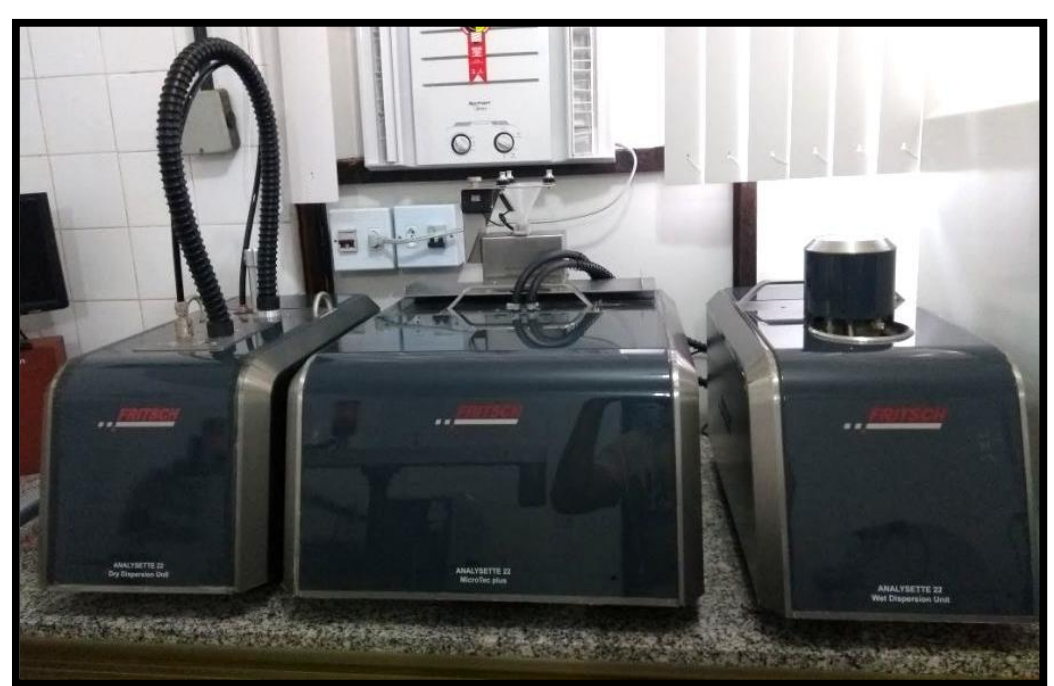

Figura 10. Vista frontal do Analisador de tamanho de partícula.

Marca e modelo: FRITSCH/ ANALYSETTE 22

Projeto: PRONEX e PRONEX-I

\subsection{PRINCÍPIOS E APLICAÇÕES}

A difração a laser mede as ditribuições de tamanho de partículas. Para o equipamento em questão a faixa de medida pode variar de 0,01 até $2100 \mu \mathrm{m}$. A medida será determinada conforme o ângulo formado entre a luz dispersa e o feixe de laser. Partículas grandes dispersam a luz em pequenos ângulos e partículas pequenas dispersam a luz em ângulos grandes. É aplicável a sólidos e suspensões. 


\section{ESPECTRÔMETRO PORTÁTIL POR FLUORESCÊNCIA DE RAIOS-X}

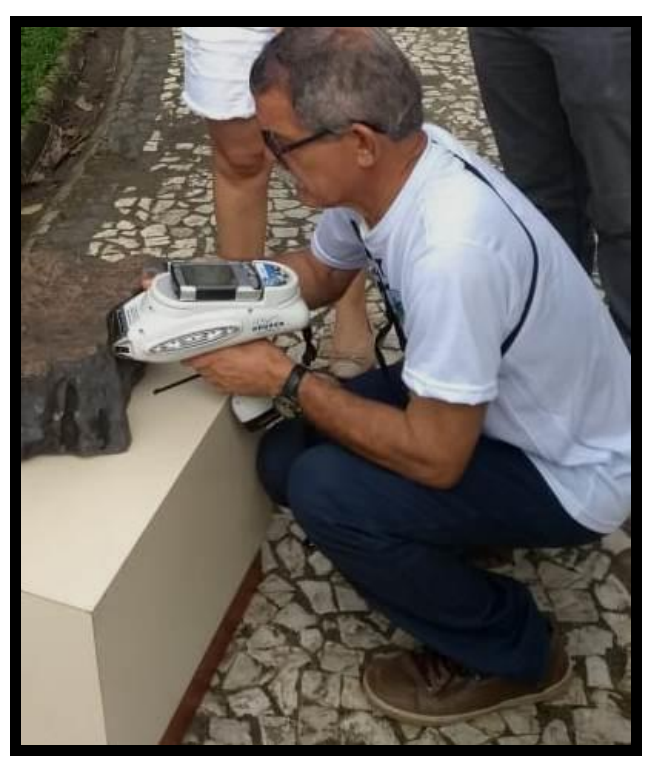

Figura 11. Espectrômetro portátil por fluorescência de raios-X.

Marca e modelo: BRUKER/S1 TURBO ${ }^{\mathrm{SD}} \mathrm{LE}$

Financiador: 01.13.0144.00 277 FINEP/FNDCT

Identificação FADESP: 9004.1.1.061014

Projeto FADESP: 3369

\subsection{PRINCÍPIOS E APLICAÇÕES}

O analisador tem característica não-destrutiva e proporciona a execução de ensaios analíticos em segundos por apresentar Detector por Deriva de Silício (SDD) com limites de detecção na ordem de ppm. Porta uma biblioteca padrão para ligas metálicas e é capaz de determinar 28 elementos, incluindo os mais leves como $\mathrm{Mg}, \mathrm{Al}$, e Si sem auxílio de vácuo ou mesmo atmosfera de He. Sua fonte de excitação é um tubo de raios-x com alvo de Ag, com voltagem máxima de 40 kV. 


\section{MEV DE BANCADA COM SED}

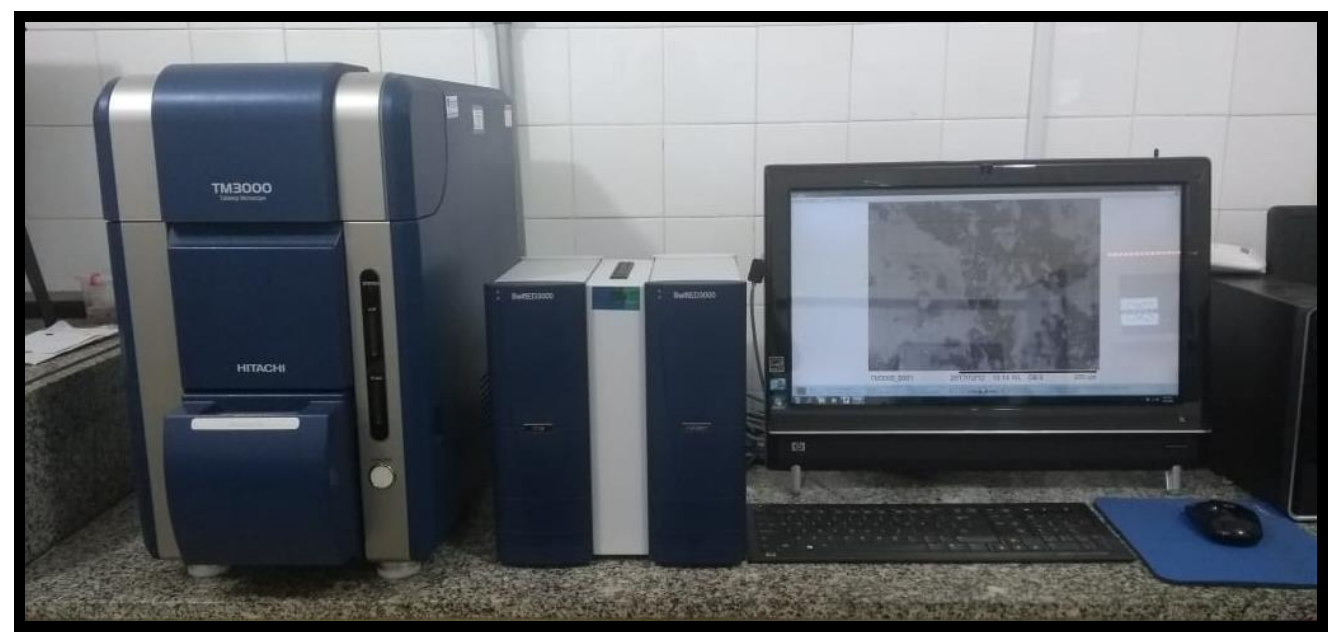

Figura 12. Vista frontal do Microscópio Eletrônico de Varredura com Sistema de Energia Dispersivo (MEV-SED).

Marca e modelo MEV: HITACHI/TM 3000

Marca e modelo SED: Oxford Instruments/SwiftED3000

Projeto: Pró Equipamentos

Tombamento Universidade Federal do Pará: 249.777

\subsection{PRINCÍPIOS E APLICAÇÕES}

O microscópio eletrônico possui um poder de resolução muito maior que o microscópio óptico, e, ao contrário deste que usa a luz, o MEV utiliza feixe de elétrons e lentes eletromagnéticas para observação do objeto em questão. O TM 3000 é uma versão compacta e utiliza um feixe de elétrons com aceleração na faixa de 5-15 kV, com ampliação de 15 a 30000x (zoom digital), imagens topográficas, sem requerer preparo da amostra, mesmo para àquelas grandes (até $70 \mathrm{~mm}$ de diâmetro e $50 \mathrm{~mm}$ de espessura) ou não condutivas, e opera sob o princípio de baixo vácuo. E, por ser integrado a um Sistema de Energia Dispersivo, ainda oferece a possibilidade de análises químicas, pontuais, ou, se necessário, através do controle de feixe digital varreduras em linha ou mapeamento químico.

O equipamento apresenta algumas restrições quanto ao tipo de material que pode ser investigado pela técnica. Em geral, trata-se de amostras que podem vir a causar algum dano ao sistema, dentre eles encontram-se: 
- Balões inflados, ovos, frutas e legumes, e organismos vivos.

OBS.: Poderão ser observados após tratamento adequado.

- Amostras no estado líquido

- Isoladores

- Amostras magnéticas

\section{FLUORESCÊNCIA DE RAIOS X DE BANCADA}

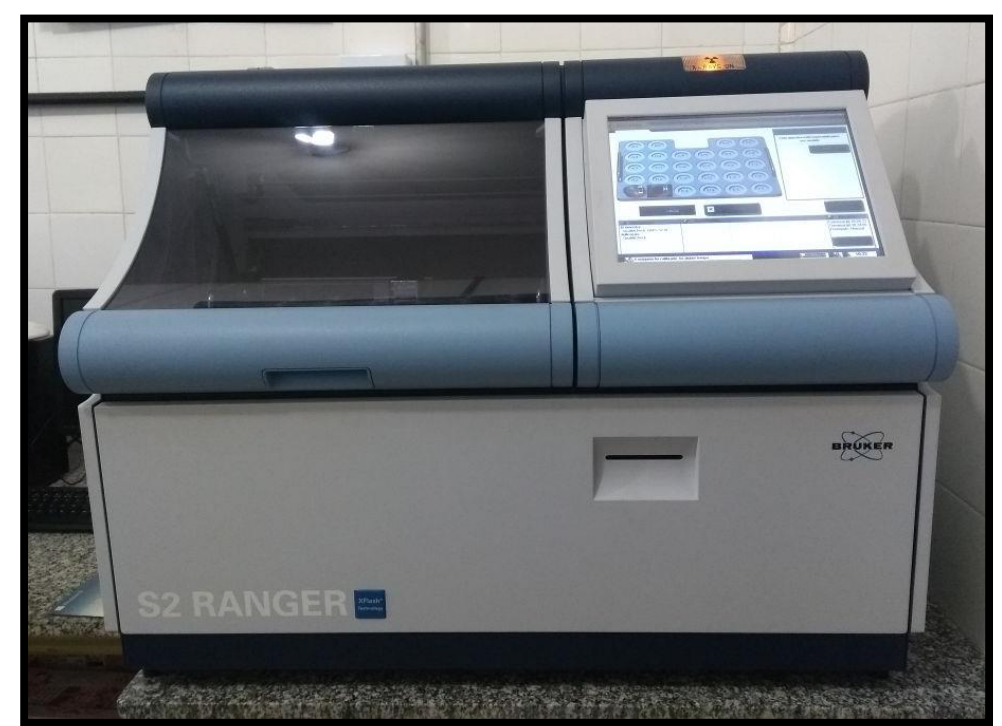

Figura 13. Vista frontal da Fluorescência de raios x.

Marca e modelo: BRUKER / S2 RANGER

Financiador: 01.13.0144.00 277 FINEP/FNDCT

Identificação: 9004.1.1.130415

Projeto FADESP: 3369

\subsection{PRINCÍPIOS E APLICAÇÕES}

A fluorescência de raios x por dispersão de energia (EDXRF) é uma técnica analítica multielementar quantitativa. O S2 Ranger, presente no LaMiGA - Raios $\mathrm{X} / \mathrm{MEV}$ apresenta capacidade para identificar elementos com número atômico no intervalo de $\mathbf{1 2} \leq \mathbf{Z} \leq \mathbf{9 2}$ a nível ppm, em sólidos, pós ou líquidos, após processamento adequado, prensagem ou fusão alcalina. Utiliza como fonte de excitação tubos de raios $\mathrm{x}$ que provocam as transições dos elétrons das camadas mais internas dos átomos, 
emitindo raios $\mathrm{X}$ com comprimento de onda e energia intrínseco de cada elemento, identificado no detector com tecnologia do tipo SDD.

\section{DIFRATÔMETRO DE RAIOS $X$}

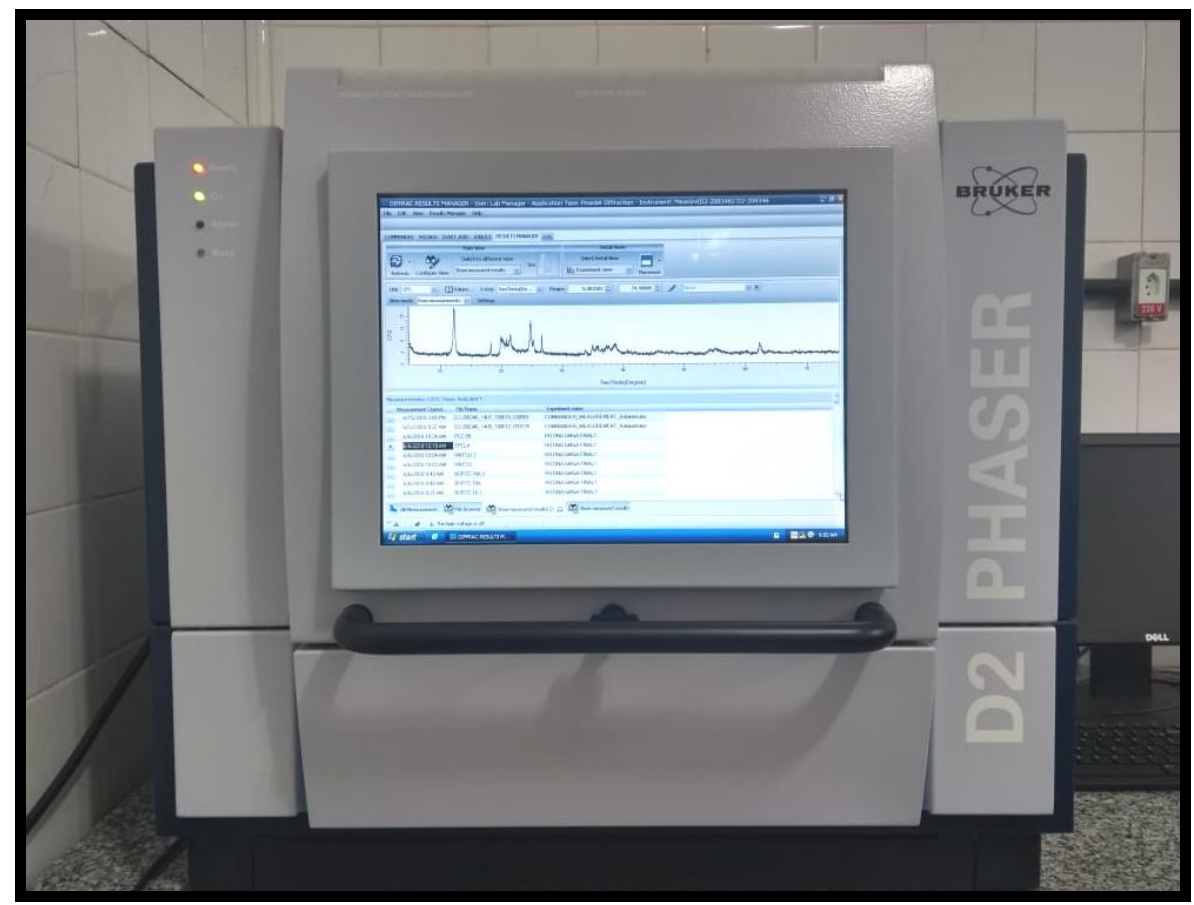

Figura 14. Vista frontal do difratômetro de raios $x$.

Marca e modelo: BRUKER / D2 PHASER

Financiador: 0110066400-0733/10 FINEP/FNDCT

Identificação: 9004.2.1.271014

Projeto FADESP: 278

\subsection{PRINCÍPIOS E APLICAÇÕES}

A difratometria de raios $\mathrm{x}$ é uma técnica usada para determinar a estrutura atômica e molecular de compostos cristalinos, na qual os átomos constituintes da amostra difratam um feixe de elétrons incidente, em muitas direções específicas. A medida dos ângulos e das intensidades dos feixes difratados permitem a identificação de fases minerais, sua quantificação e a determinação de seu grau de ordenamento estrutural. 


\section{ESPECTRÔMETRO PORTÁTIL por $\mu$-FRX - ARTAX}

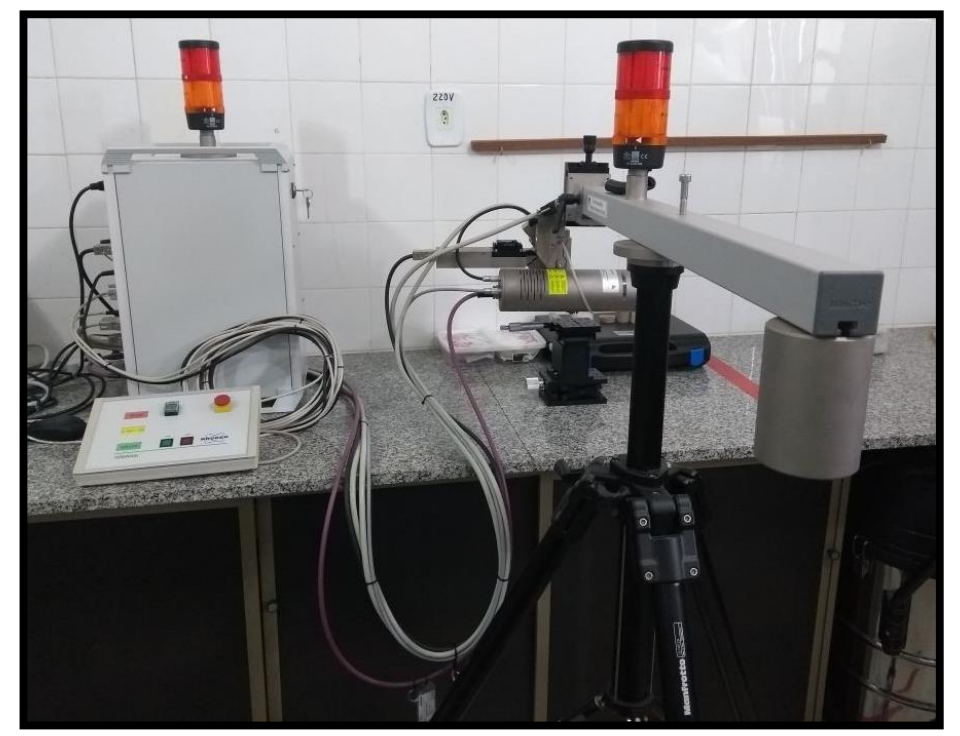

Figura 15. Espectrômetro portátil por $\mu$-FRX - ARTAX.

Marca e modelo: BRUKER / ARTAX 200.

\subsection{PRINCÍPIOS E APLICAÇÕES}

A $\mu$-FRX portátil instalada em julho de 2015 trata-se de uma técnica não-destrutiva, que permite análise multielementar, qualitativa e quantitativa, em uma investigação espacial de distribuição de elementos, com resolução de até $70 \mu \mathrm{m}$, no intervalo de elementos do $\mathrm{Na}(Z=11)$ ao $\mathrm{U}(Z=92)$. É bastante eficaz na análise de obras de arte in situ como pinturas em tela, em parede, em teto, graças à mobilidade do braço que contêm a fonte de excitação, as lentes policapilares, o detector de energia dispersiva e a câmera integrada CCD, no eixo X-Y-Z posicionando o feixe ao objeto sob investigação e não o inverso. 


\section{Universidade Federal do Pará} Instituto de Geociências

Programa de Pos-Graduação em Geologia e Geoquímica

\section{LaMiGA - FTIR/ATD-TG/BET}

Laboratório de Mineralogia, Geoquímica e Aplicações

(INFRAVERMELHO, ANÁLISE TERMOGRAVIMÉTRICA, ADSORÇÃO NITROGÊNIO)

Responsável: Prof. Dr. Marcondes Lima da Costa

Contatos: 3201-7428/marcondeslc@gmail.com

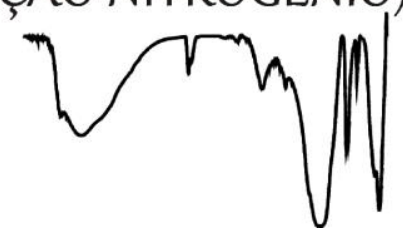




\section{RECURSOS HUMANOS}

EQUIPE: Dra. Glayce Jholy S.S. Valente

MSc. Igor Alexandre Rocha Barreto

MSc. Pabllo Henrique Costa dos Santos

\section{INSTALACÕES}

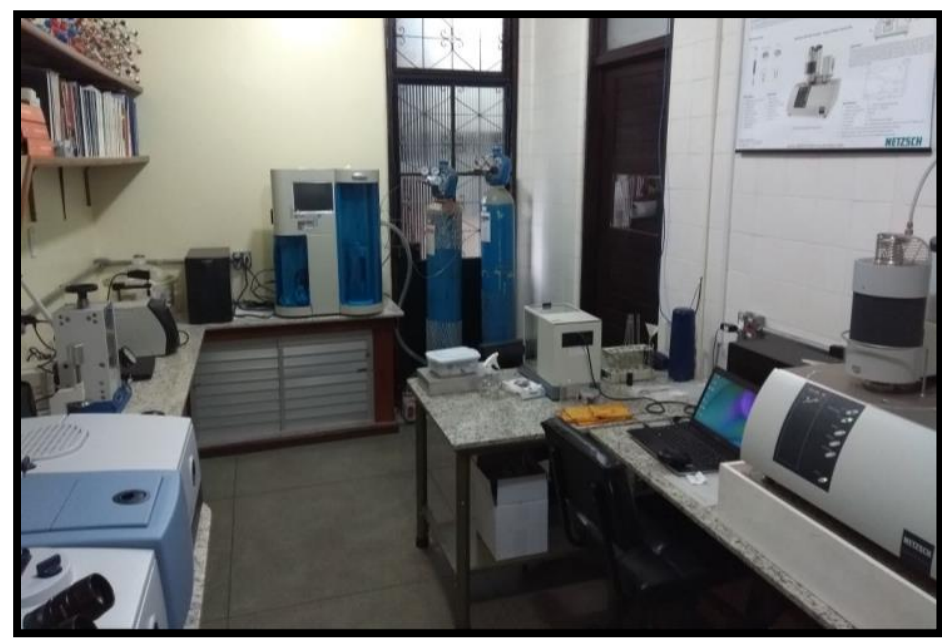

Figura 16. Espaço físico do LaMiGA - FTIR/ATD-TG/BET.

1. ESPECTRÔMETRO INFRAVERMELHO POR TRANFORMADA DE FOURIER (FT-IR)

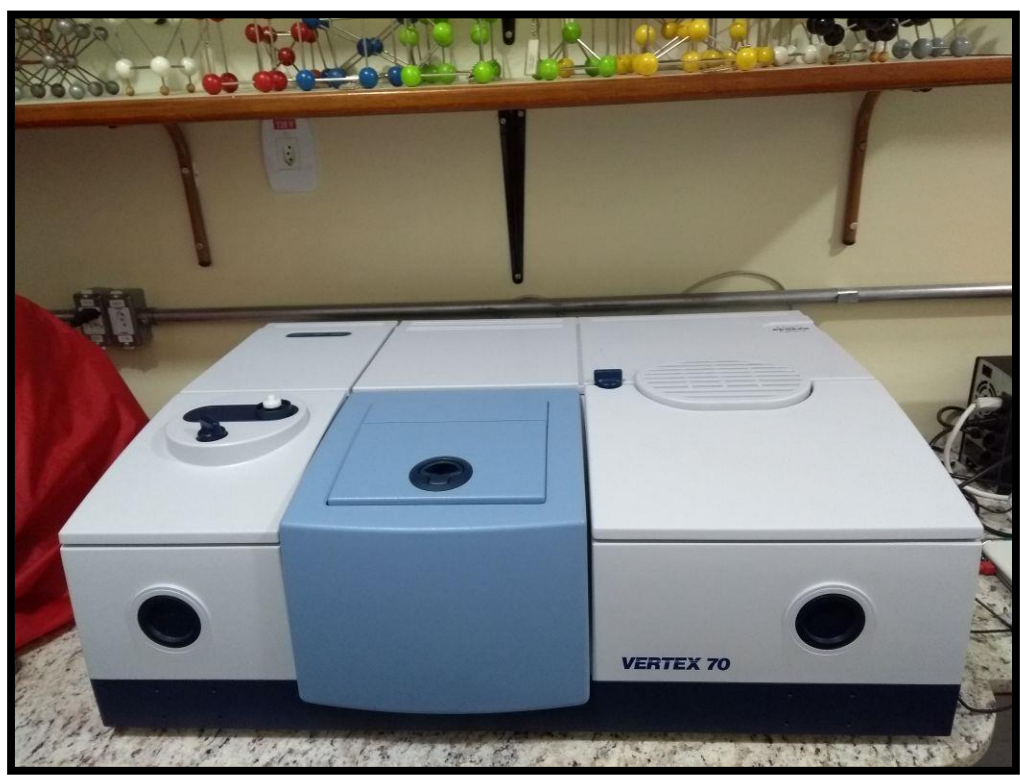

Figura 17. Vista superior e frontal do FTIR. 
Marca e modelo: BRUKER / VERTEX 70

Projeto: PRONEX.

\subsection{PRINCÍPIOS E APLICAÇÕES}

A espectroscopia na região do infravermelho é uma técnica que fornece energia na ordem de 2 a $15 \mathrm{Kcal}$, por isso, tende a afetar as ligações químicas de moléculas apenas a níveis vibracionais, pois, interfere na amplitude dos movimentos periódicos entre átomos de uma mesma molécula em relação à posição relativa entre eles. Os tipos de vibrações variam de acordo com a quantidade de átomos, e podem ser axiais ou angulares.

O campo de aplicação para a técnica é bastante vasto, visto que, proporciona a utilização de materiais tanto em estado sólido, sendo o mais comum o preparo de pastilhas prensadas e até mesmo de líquidos, de acordo com o acessório adequado.

\section{ANALISADOR DE ÁREA SUPERFICIAL E DISTRIBUIÇÃO DE TAMANHO}

\section{E VOLUME DE PORO - BET}

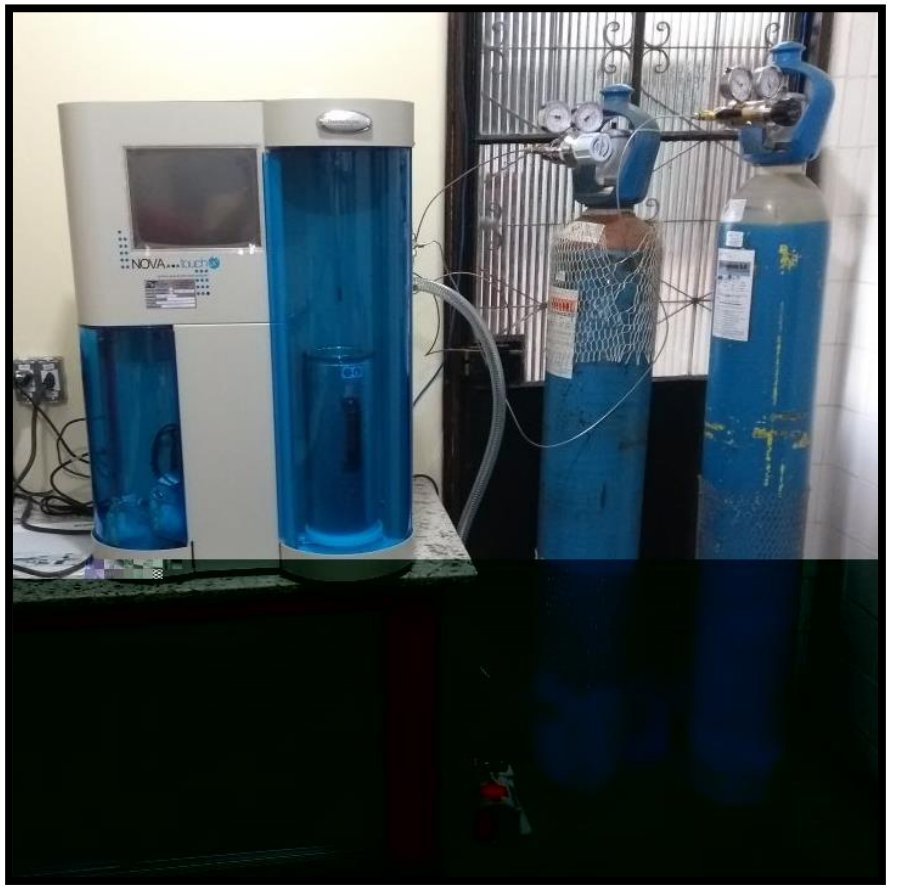

Figura 18. Vista frontal do BET. 
Marca e modelo: Quantachrome / Novatouche LX ${ }^{3}$

Análise: área superficial e distribuição de tamanho e volume de poro.

\subsection{PRINCÍPIOS E APLICAÇÕES}

É uma técnica analítica que tem como base uma teoria matemática (conforme BET - Brunauer-Emmett-Teller) que objetiva descrever a adsorção física de moléculas de um gás inerte sobre uma superfície sólida e seca para formar uma camada mono molecular, e serve como base importante para medição de área superficial específica de um material, e distribuição de tamanho e volume de poros.

\section{ANÁLISE TÉRMICA E TERMOGRAVIMÉTRICA}

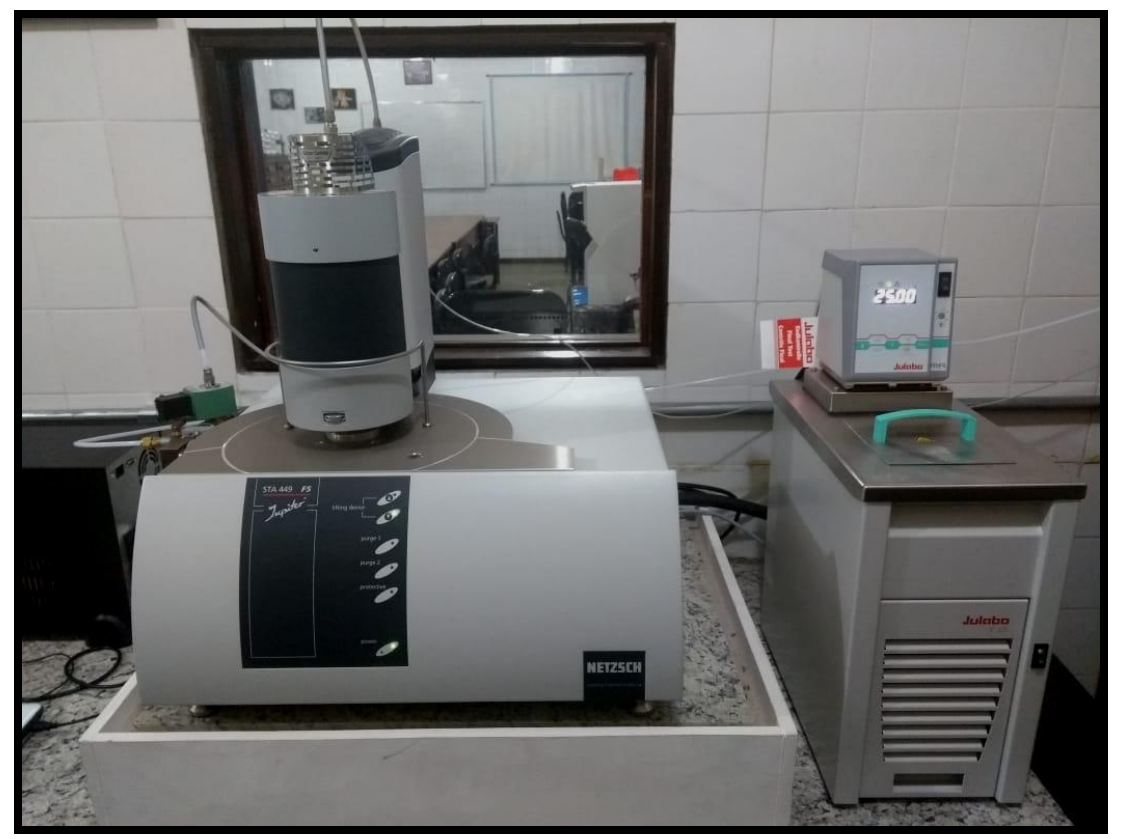

Figura 19. Vista frontal do analisador térmico.

Marca e modelo: NETZSCH / STA 449 F5 Jupiter

\subsection{PRINCÍPIOS E APLICAÇÕES}

É o acoplamento de duas técnicas de análise térmica que têm como objetivo avaliar as propriedades físicas em função da temperatura, refletindo mudanças físicas e químicas que ocorrerem nos materiais sob análise. 
TG ou TGA monitora a mudança de massa em função da temperatura e do tempo.

DSC monitora os eventos que envolvem troca de calor: endotérmico e exotérmico.

\section{ESPECTRÔMETRO $\mu$-RAMAN GemRam (Raman Gemstone Identification System)}

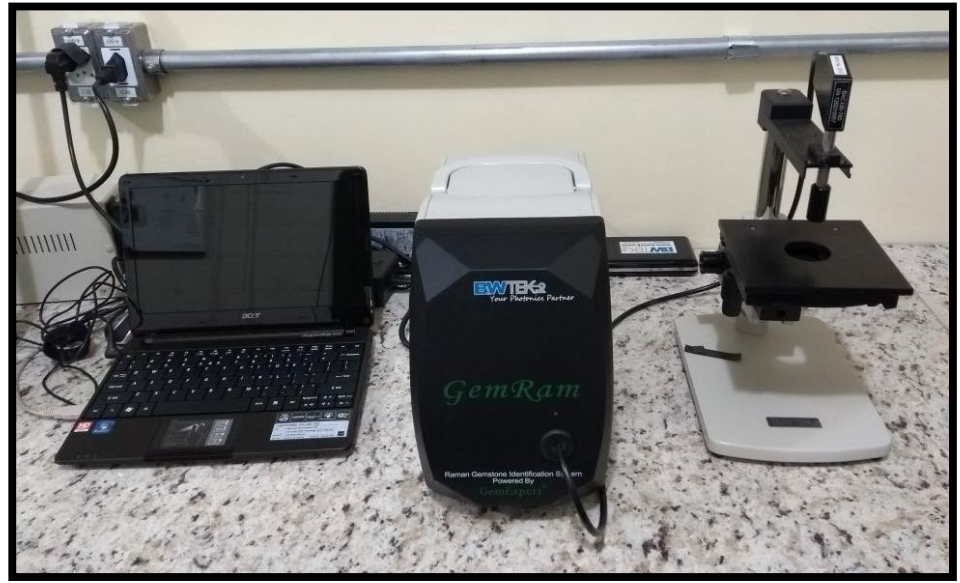

Figura 20. Vista superior e frontal do espectrômetro $\mu$-Raman.

Marca e modelo: B $_{\&}$ WTEK'S /GEMRAM ${ }^{\mathrm{TM}}$

Financiador: Pró Equipamentos

Tombamento: Universidade Federal do Pará: 297.600

\subsection{PRINCÍPIOS E APLICAÇÕES}

O sistema GemRam é voltado para identificação de pedras preciosas, é alimentado pela biblioteca espectral da GemExpert de quase 400 gemas diferentes para todas as classes, incluindo: boratos, carbonatos, haletos, elementos nativos, óxidos, fosfatos, silicatos, sulfatos e sulfetos. O software de identificação é o GemID patenteado pela B \& W Tek. 


\section{MICROSCÓPIO PETROGRÁFICO}

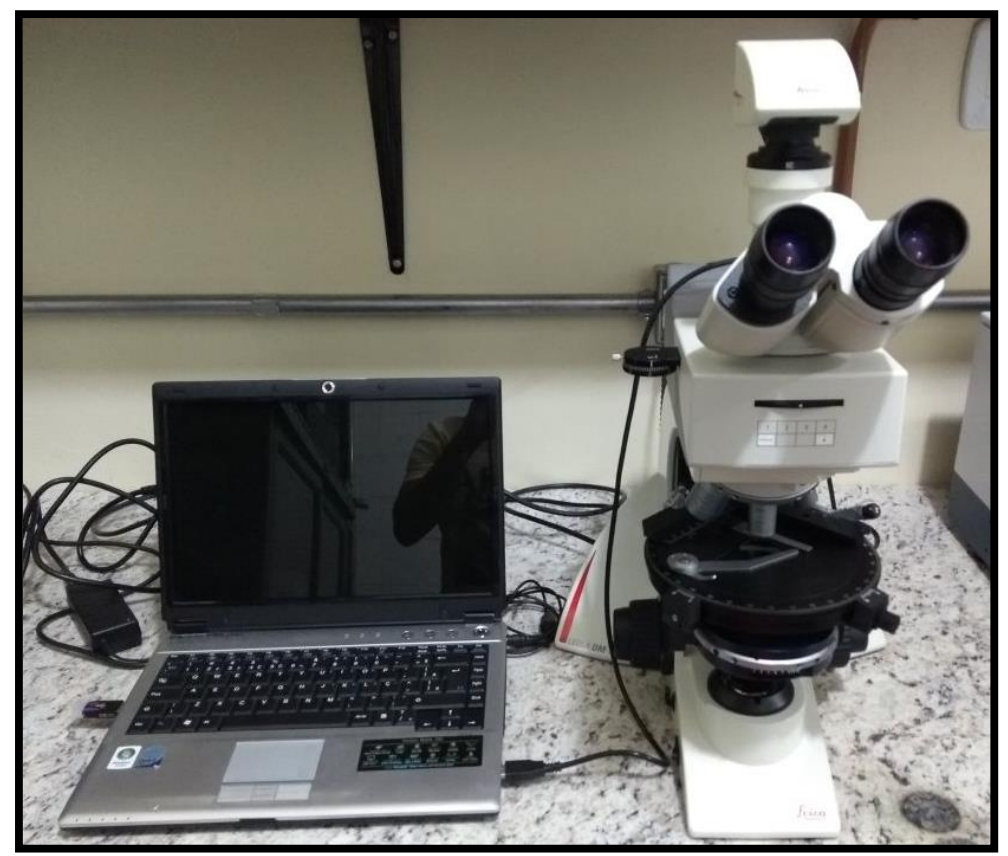

Figura 21. Vista superior e frontal do microscópio.

Marca / modelo: Leica / DM 2700 P

Análise: imageamento com aumento de até 50x.

\subsection{PRINCÍPIOS E APLICAÇÕES}

O microscópio petrográfico utiliza luz transmitida ou refletida com o intuito de analisar amostras de rochas e minerais dispostas em lâminas delgadas ou seções polidas. Este equipamento utiliza dois filtros polarizadores no caminho da luz - acima e abaixo da amostra - sendo um deles analisador e o outro polarizador. A forma como o objeto analisado interage com a luz polarizada fornece informações sobre sua composição mineralógica, já que os minerais possuem propriedades ópticas conhecidas. A microscopia de polarização pode ser usada com luz transmitida e refletida. A primeira é indicada para o estudo de minerais transparentes, como a maioria dos silicatos; e a segunda é empregada para os minerais opacos tais como óxidos e sulfetos. $\mathrm{O}$ aumento máximo é de 50 vezes. 
Universidade Federal do Pará

Instituto de Geociências

Programa de Pos-Graduação em Geologia e Geoquímica

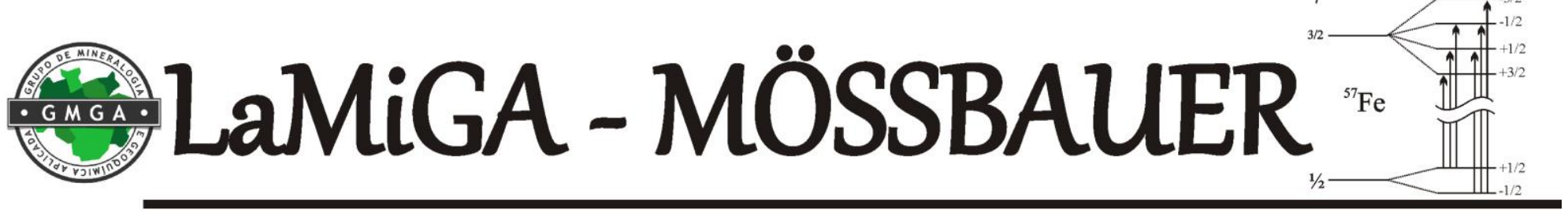

Laboratório de Mineralogia, Geoquímica e Aplicações (ESPECTROSCOPIA MÖSSBAUER)

Responsáveis: Prof. Dr. Marcondes Lima da Costa, Prof. Dr. Nilson dos Santos Ferreira (UFS) Contatos: 3201-7428/marcondeslc@gmail.com/nilsondsf@gmail.com 


\section{RECURSOS HUMANOS}

EQUIPE: Dra. Glayce Jholy S.S. Valente

MSc. Pabllo Henrique dos Santos Costa

Prof. Dr. Nilson dos Santos Ferreira

\section{INSTALACÕES}

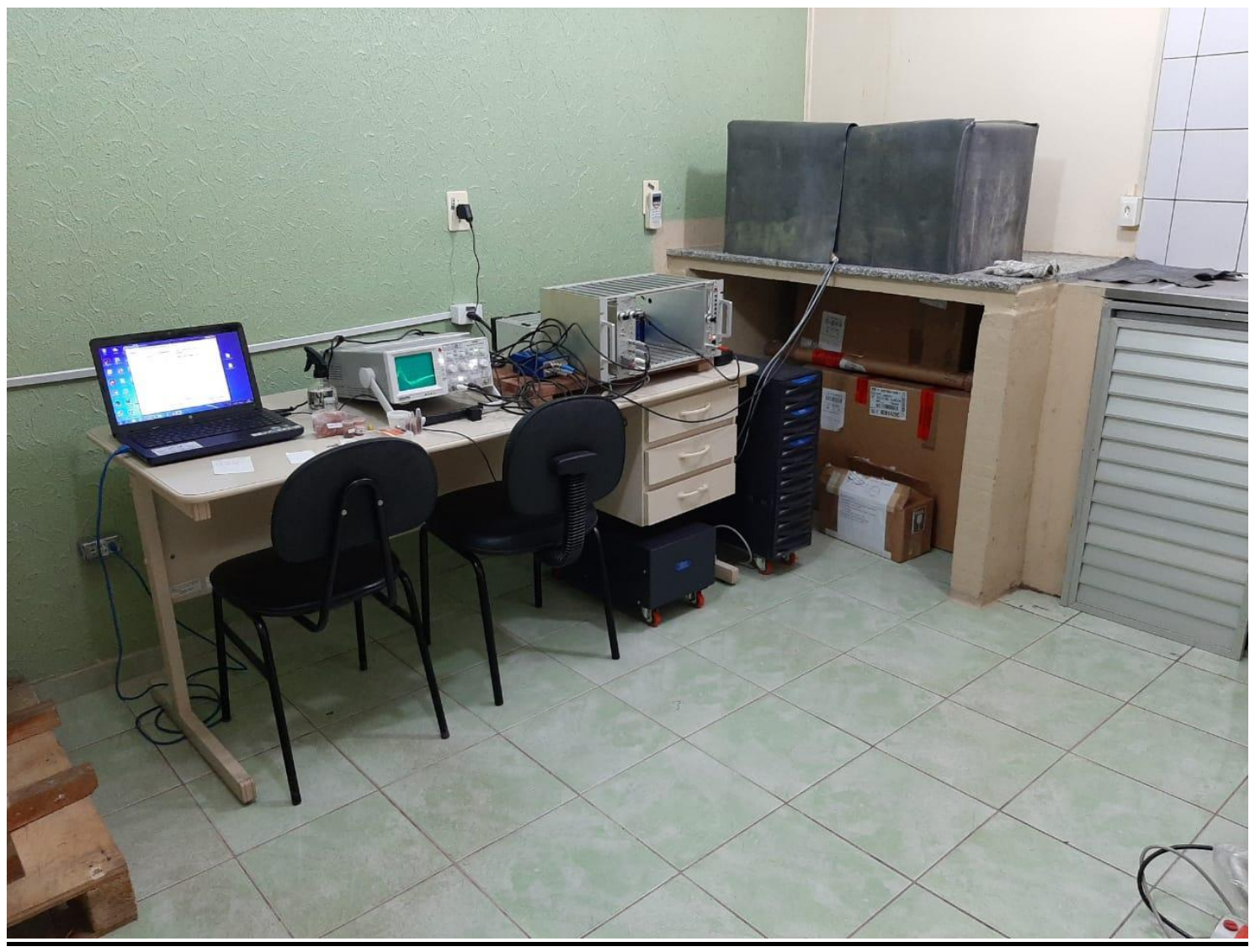

Figura 22. Vista geral do laboratório LaMiGA - Mössbauer.

\section{HISTÓRICO DO LABORATÓRIO}

É o mais recente espaço nomeado como laboratório quase concomitante à chegada e instalação do equipamento ocorridos em 2017 e 2018, respectivamente. Trata-se de um espaço pequeno que assim como os demais sofreu modificações principalmente em relação às suas condições elétricas. Localiza-se de maneira adjacente ao Instituto de Geociências, próximo a entrada dos fundos. 


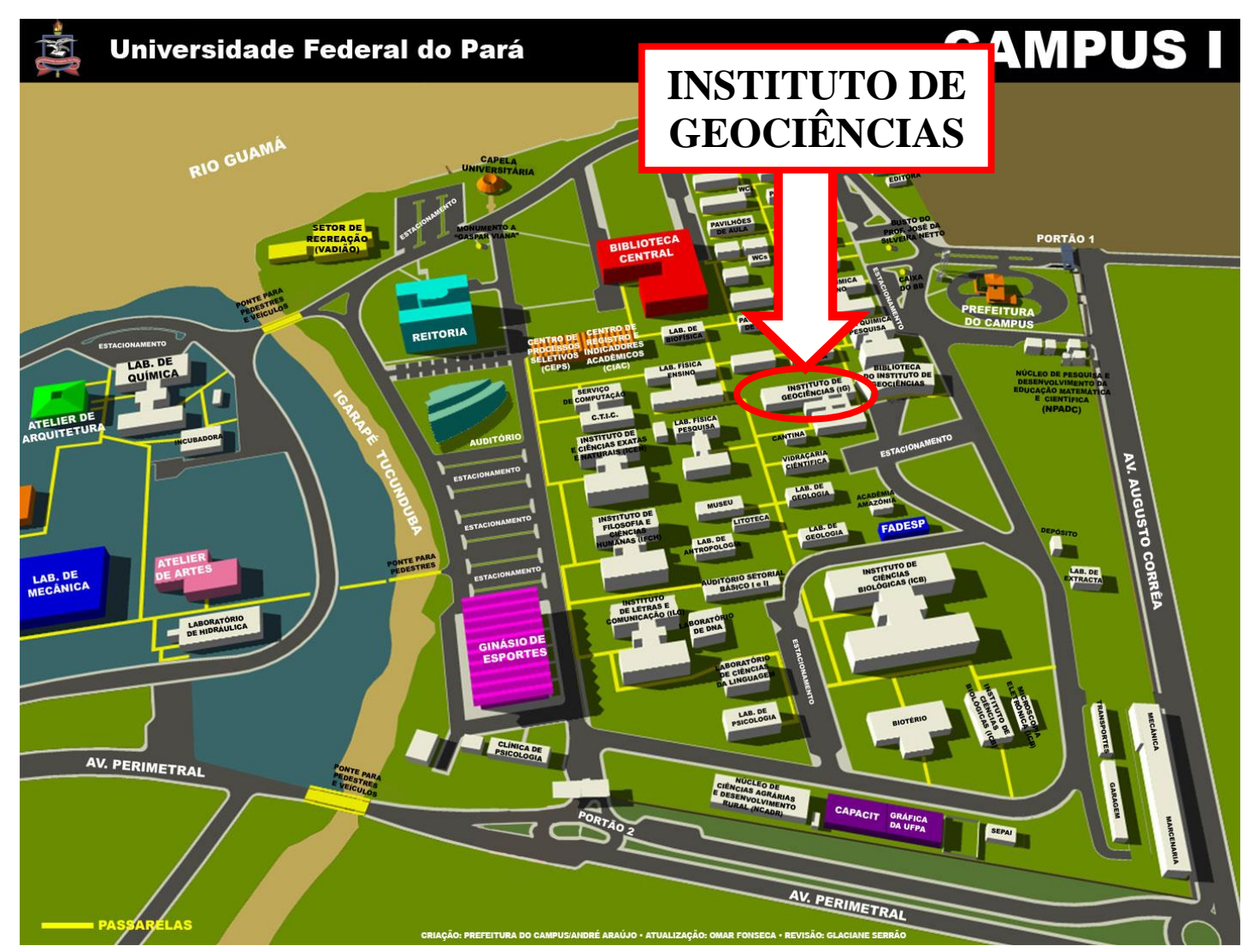

Figura 23. Localização do laboratório LaMiGA - Mössbauer no Campus UFPA. 


\section{EQUIPAMENTO}

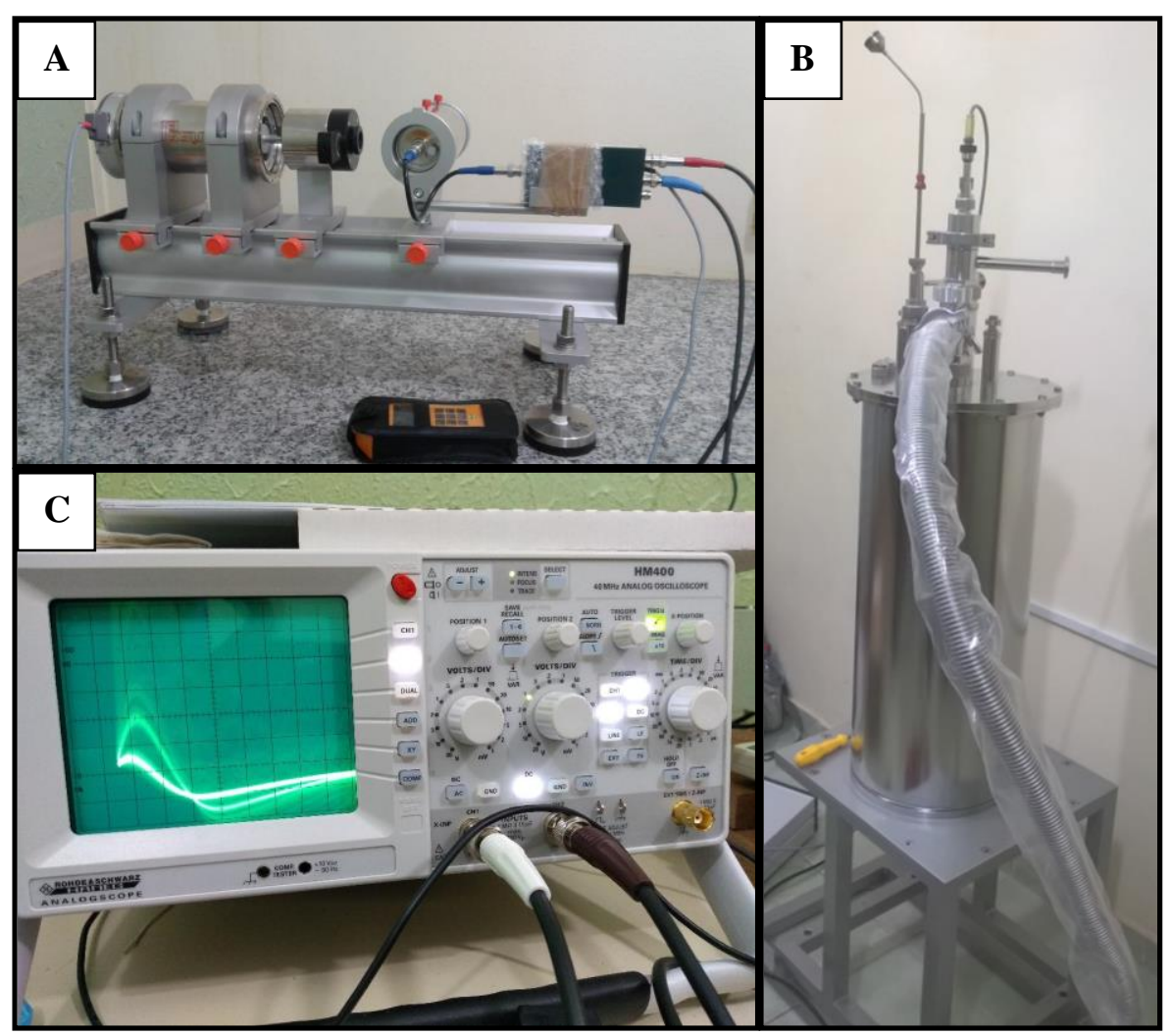

Figura 24. Componentes da estrutura de espectroscopia Mössbauer. A: Pré-amplificador, amplificador, fonte de ${ }^{57} \mathrm{Co}$, transdutor de velocidade. B: Equipamento de baixa temepartura - Criostato. C: Osciloscópio.

\section{$\underline{\text { Sistemas de Instrumentacão Mössbauer }}$}

\section{Lista de instrumentos:}

Marca / modelo: WissEl - Wissenschaftliche Elektronik GmbH

Unidade de acionamento/modelo: MRG-500

Transdutor de velocidade/modelo: MA-260S

Pré-amplificador + amplificador principal/modelo: PEA-6A

Módulo de aquisição de dados/modelo: CMCA-550

Fonte de alimentação de alta tensão/modelo: HVS-2

Equipamento de baixa temperatura/modelo: Criostato MBBC-HE0106 He/ $\mathrm{N}_{2}$ 
Software de tartamento dos dados: WinNormos-for-Igor®

Fonte de energia: NIM Bin S7029

Configuração mecânica: MB-500 Mössbauer Bench

Fonte de radiação gama: ${ }^{57} \mathrm{Co}$ em matriz de $\mathrm{Rh}$

Calibrador de velocidade: Interferômetro a laser MVC-450 com módulo NIM

Osciloscópio analógico: HM400

\section{PRINCÍPIOS E APLICAÇÕES}

A espectroscopia Mössbauer consiste no estudo das energias emitidas entre as transições dos estados nucleares e envolve a possibilidade de ocorrer emissão e absorção de raios gama, $\gamma$, sem recuo (ou fluorescência de raios gama) conhecido como Efeito Mössbauer (absorção ressonante nuclear sem recuo) para identificar espécies químicas em materiais sólidos. As interações nucleares normalmente observadas são: deslocamento de isômero, divisão quadrupolar e divisão hiperfina magnética.

A aplicabilidade da técnica é bastante versátil e pode se empregada na resolução de questões nas áreas da química, física, biologia e metalurgia. Ou seja, a uma diversidade de materiais fornecendo informações sobre propriedades químicas, estruturais e magnéticas. 
Universidade Federal do Pará Instituto de Geociências

Programa de P6s-Graduação em Geologia e Geoquímica

Laboratório de Mineralogia, Geoquímica e Aplicações

(MICROSCÓPIOS, ESTEREOSCÓPIOS, BALANÇAS, COLEÇÕES)

Responsável: Prof. Dr. Marcondes Lima da Costa

Contatos: 3201-7428/marcondeslc@gmail.com

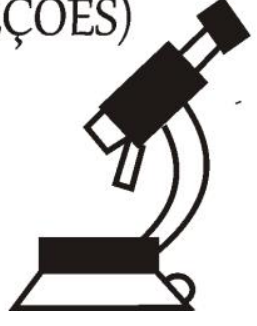




\section{RECURSOS HUMANOS}

EQUIPE: MSc. Pabllo Henrique Costa dos Santos

Bacharel em geologia Rayara do Socorro Souza da Silva

INSTALACÕES

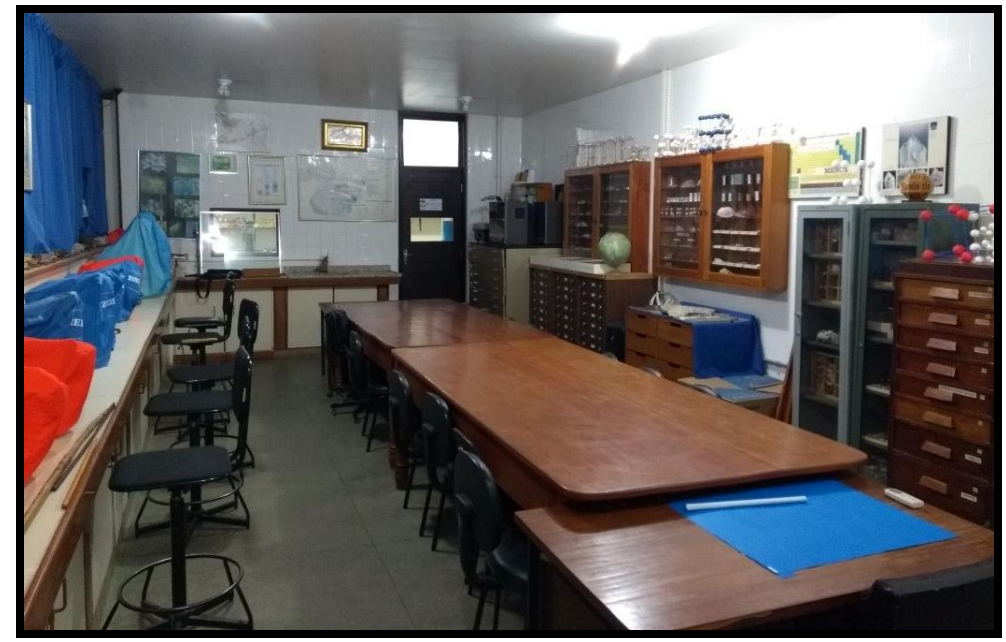

Figura 25. Vista geral do LAMIGA mineralogia/gemologia.

\section{COLEÇÕES}

O laboratório de mineralogia/gemologia além dos equipamentos descritos a seguir dispõe de coleções de rochas e minerais utilizadas em disciplinas para alunos de graduação e pós graduação. Uma delas é a Coleção Ward's Natural Science Establishment Rochester, N.Y, da empresa fundada a 150 anos pelo geólogo e naturalista Henry Augustus Ward na cidade de Rochester, que se inicou com a coleta de espécimes de todas a partes do mundo, cujas montagens eram vendidas para faculdades e museus. A outra coleção disposta no armário identificado como "monstruário" acarreta amostras de minerais e rochas também das mais diversas localidades nacionais e de outros países também utilizadas em sala de aula. 


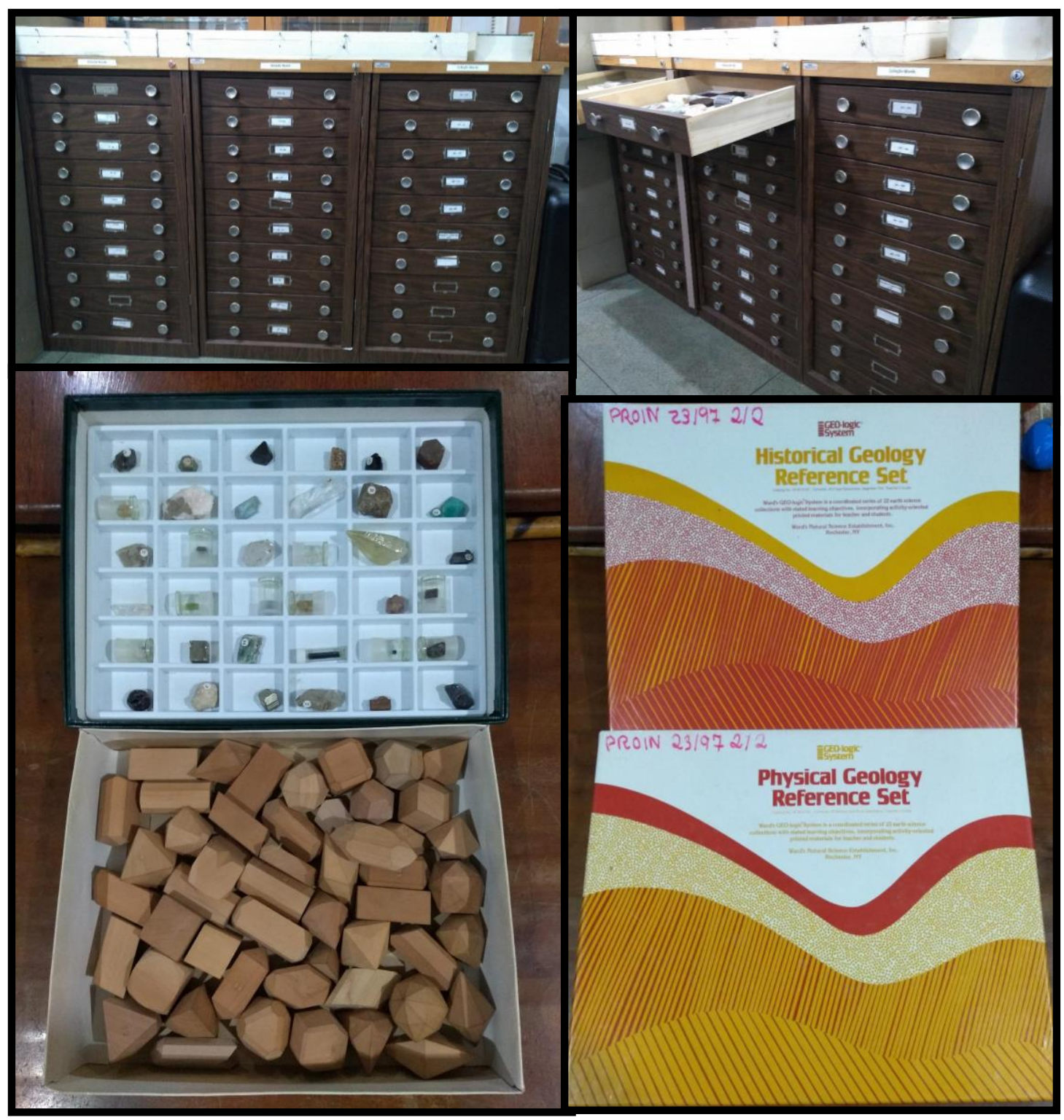

Figura 26. Coleção Ward's LAMIGA mineralogia/gemologia 


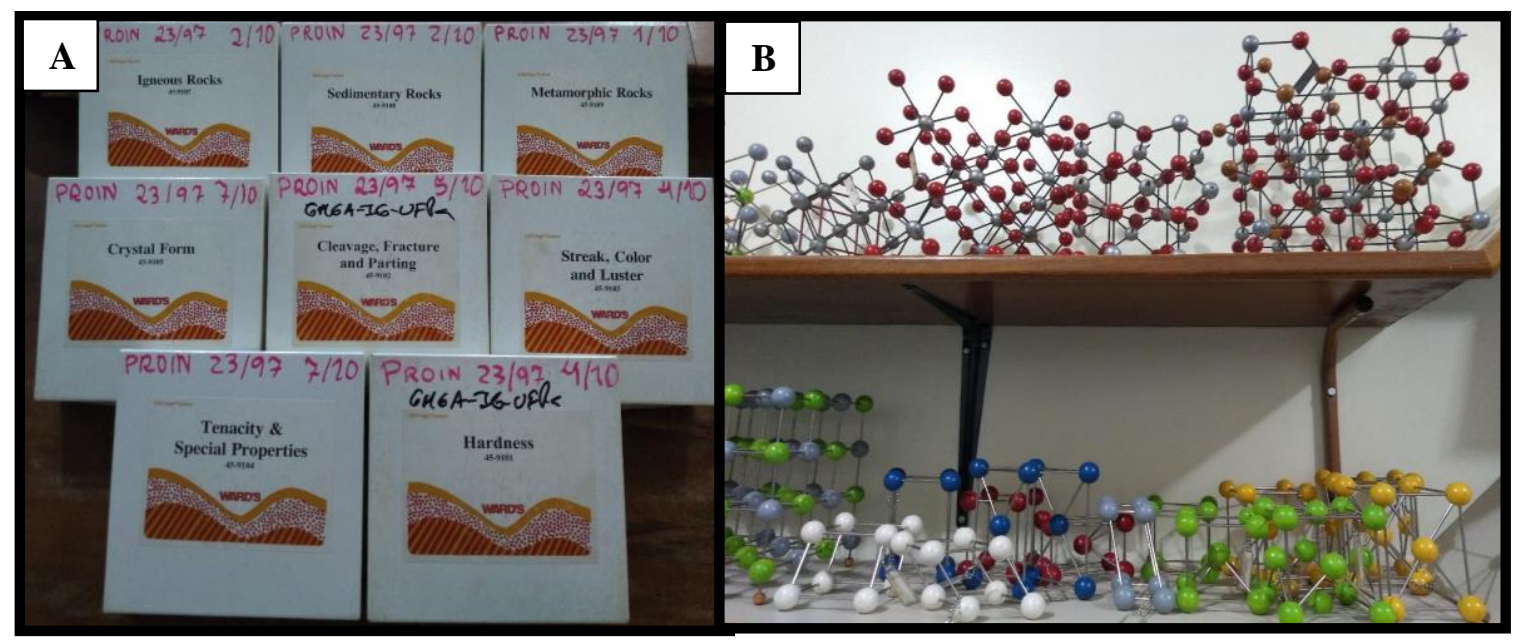

Figura 27. A: Coleção Ward's: propriedades físicas dos minerias, classificação de rochas, B: modelos de estruturas cristalinas. LAMIGA mineralogia/gemologia.

\section{MICROSCÓPIO PETROGRÁFICO}

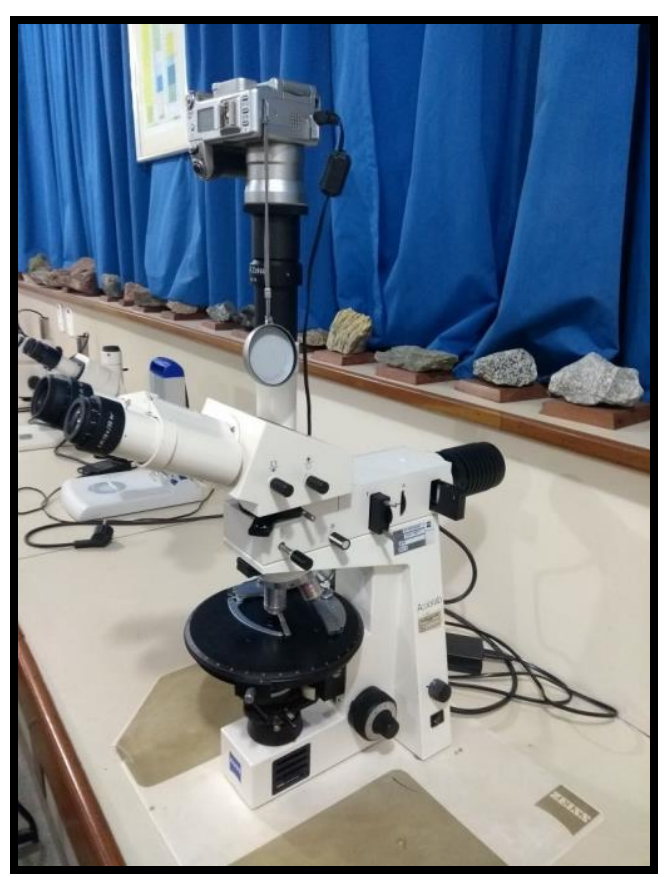

Figura 28. Microscópio petrográfico da marca Zeizz e modelo Axiolab.

\subsection{PRINCÍPIOS E APLICAÇÕES}

Este microscópio petrográfico utiliza luz transmitida com o intuito de analisar amostras de rochas e minerais dispostas em lâminas delgadas. Este equipamento utiliza 
dois filtros polarizadores no caminho da luz - acima e abaixo da amostra - sendo um deles analisador e o outro polarizador. A forma como o objeto analisado interage com a luz polarizada fornece informações sobre sua composição mineralógica, já que os minerais possuem propriedades ópticas conhecidas. A microscopia de polarização pode ser usada com luz transmitida, indicada para o estudo de minerais transparentes, como a maioria dos silicatos. O aumento máximo é de 50 vezes.

\section{ESTEREOMICROSCÓPIOS}

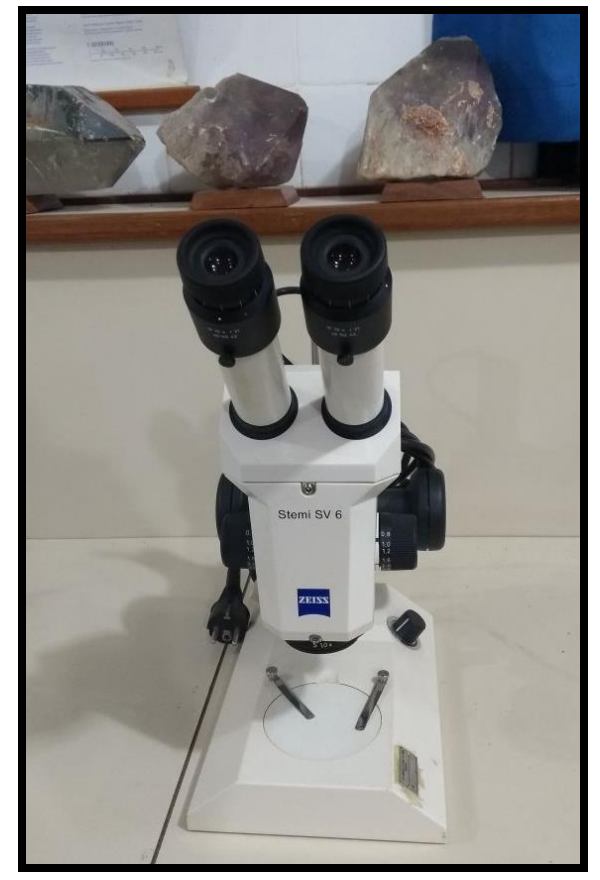

Figura 29. Estereomicroscópio binocular da marca Zeiss e modelo Stemi V6 (cinco unidades).

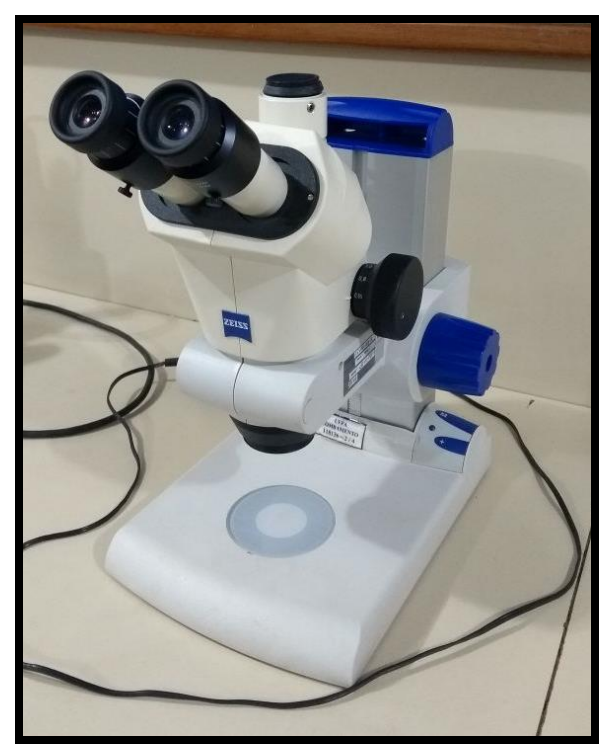


Figura 30. Estereomicroscópio binocular da marca Zeiss e modelo AxioLab.

\subsection{PRINCÍPIOS E APLICAÇÕES}

O estereomicroscópio utiliza a luz refletida, em associação a lentes com aumento de até 20 vezes, com o intuito de facilitar a descrição e identificação de materiais de dimensões milimétricas.

Belém, 11 de dezembro de 2019

Prof. Dr. Marcondes Lima da Costa

Dra. Glayce Jholy Souza da Silva Valente 